$\mathcal{G S}_{\text {http://dx.doi.org/10.3765/sp.8.6 }}^{\text {Semantics \& Pragmatics Volume 8, Article 6: 1-48, } 2015}$

\title{
The Degree Semantics Parameter and cross-linguistic variation*
}

\author{
M. Ryan Bochnak \\ University of California, Berkeley
}

Submitted 2014-05-14 / First decision 2014-07-02 / Revision received 2014-08-04 /

Accepted 2014-09-25 / Final version received 2014-11-04 / Published 2015-03-25

\begin{abstract}
The standard degree analysis of gradability in English holds that the function of degree morphology, such as the comparative, measure phrases, and degree adverbs, is to bind a degree variable located in the lexical semantics of gradable predicates. In this paper, I investigate gradation structures in Washo (isolate/Hokan), and claim that this language systematically lacks degree morphology of this sort. I propose that this gap in the functional inventory of Washo stems from variation in whether gradable predicates introduce degree variables that can be bound by such operators, providing further cross-linguistic support for a similar proposal made by Beck, Krasikova, et al. (2009) for Motu (Austronesian). Consequently, if we assume that gradable predicates in English are type $\langle d,\langle e, t\rangle\rangle$, then Washo and English must differ in their lexical semantics for gradable predicates. I also discuss an alternative account for handling the variation observed, couched within the degree-free analysis of van Rooij (2011a,b). Although this account can also capture the cross-linguistic facts, it does so at the expense of a unified analysis of degree constructions more generally. The results of this investigation inform questions about the nature of cross-linguistic
\end{abstract}

* I am deeply grateful to my Washo consultants Ramona Dick and Steven James for teaching me their language. Thanks to Karlos Arregi, Chris Barker, Rajesh Bhatt, Eva Csipak, Amy Rose Deal, Itamar Francez, Anastasia Giannakidou, Chris Kennedy, Andrew Koontz-Garboden, Jason Merchant, Galit Sassoon, Roger Schwarzschild, Judith Tonhauser, and Alan Yu for comments on various versions of this work, as well as audiences at the LSA 2012 in Portland, Oregon, NELS 42 at the University of Toronto, WSCLA 18 at the University of Chicago, University of Göttingen, University of Tübingen, Wayne State University, Swarthmore College, and the Zentrum für Allgemeine Sprachwissenschaft in Berlin. I would also like to thank associate editor Louise McNally and three anonymous reviewers who gave thorough and thought-provoking feedback, which greatly helped me improve this paper. All remaining errors are my own. This research was supported by grants from the Jacobs Fund of the Whatcom Museum, the American Philosophical Society, and the National Science Foundation under grant \#1155196.

(C)2015 M. Ryan Bochnak

This is an open-access article distributed under the terms of a Creative Commons Attribution License (http://creativecommons.org/licenses/by/3.o/). 
variation in semantics, specifically the division of labor between variation in functional categories and the lexicon.

Keywords: comparison, degrees, gradability, vagueness, cross-linguistic variation, Washo

\section{Introduction}

In what has become the standard analysis for gradable predicates in English, a gradable predicate (typically a gradable adjective) contains a degree variable, where degrees are taken as a basic semantic type $d$. The most frequent instantiation of this proposal assumes the presence of a degree argument that must be bound or saturated, yielding a predicate of individuals (Cresswell 1976, von Stechow 1984, Heim 1985, 2001, Kennedy \& McNally 2005, among others). The denotation of the gradable predicate tall is thus rendered as in (1), where $d$ is a variable over degrees, $x$ is a variable over individuals, and HEIGHT is a measure function relating $x$ to $d$, a degree on the scale of height. ${ }^{1}$

(1) $\llbracket$ tall $\rrbracket=\lambda d \lambda x$.HEIGHT $(x) \succeq d$

One of the major motivations for positing a degree variable comes from the fact that gradable predicates can combine with a host of morphology whose function is to specify something about its value. Under this system, degree morphemes are functions from gradable predicate meanings to properties of individuals. Degree morphemes differ from one another in the sort of restriction they place on the degree variable of a gradable predicate. For instance, Kennedy \& McNally (2005) model the general case as in (2), where $G$ is a gradable predicate of type $\langle d,\langle e, t\rangle\rangle$, and $\mathbf{R}$ is a variable for the restriction placed on $d$.

(2) $\llbracket \mathrm{Deg} \rrbracket=\lambda G \lambda x . \exists d[\mathbf{R}(d) \wedge G(d)(x)] \quad$ (Kennedy \& McNally 2005, p. 367)

1 A line of research has argued for an analysis of gradable predicates simply as measure functions of type $\langle e, d\rangle$ (Bartsch \& Vennemann 1972, Kennedy 1997, 2007b):

(i) $\llbracket$ tall $\rrbracket=\lambda x$. $\operatorname{HEIGHT}(x)$

Since this view of gradable predicates also makes use of a degree variable of type $d$ in the basic ontology, for the purposes of this paper the 'measure function' analysis will be taken to be equivalent to the 'degree argument' analysis. 
Degree semantics and cross-linguistic variation

Among the degree morphemes analyzed in this way are the comparative morpheme, where $\mathbf{R}$ imposes the restriction that $d$ be greater than some other degree derived from the comparative clause, and measure phrases, where $\mathbf{R}$ restricts $d$ to degrees greater than or equal to the degree named by the measure phrase. ${ }^{2}$ In the case where no overt degree morphology is present (i.e., with the absolute or positive form of the adjective as in Kim is tall) the null degree morpheme pos binds the degree variable and introduces a contextual standard. The formulation of pos in (3) is adapted from Kennedy \& McNally (2005), where $s_{G}$ is the standard for $G .^{3}$

\section{(3) $\llbracket p o s \rrbracket=\lambda G \lambda x \cdot \exists d\left[d \succ s_{G} \wedge G(d)(x)\right]$}

In the first part of this paper, I examine gradation structures in Washo (isolate/Hokan; California \& Nevada), a language that systematically lacks degree morphology of the type in (2) (Bochnak 2013). For instance, to make comparisons, Washo speakers make use of a conjunctive strategy like in (4), whereby two full clauses containing antonymous predicates are juxtaposed, but without any dedicated comparative morphology marking the gradable predicate or the standard of comparison (Stassen's (1985) so-called 'conjoined comparison' construction). ${ }^{4}$

2 This simplistic view glosses over many details of the syntax and semantics of comparatives and measure phrases. What is important here is that these are all members of the paradigm of degree morphology, which is the crucial feature that Kennedy \& McNally's analysis shares with other degree-based accounts.

3 Under a different implementation, the contextual standard is introduced by the silent degree modifier EVAL. See Rett (2007) for details.

4 Washo is a highly endangered language spoken in the Lake Tahoe region of California and Nevada. All Washo data come from primary fieldwork unless otherwise noted. See Bochnak (2013) and Bochnak \& Bogal-Allbritten (2015) for methodological discussion on conducting fieldwork on degree constructions, and Matthewson (2004) on semantic fieldwork methodology more generally. The orthography used for Washo examples is adapted from Jacobsen (1964), where most characters generally correspond with their IPA values, with the following exceptions: $c=$ [ts] $L=[1] ; M=[\mathrm{m}] ; \check{s}=\left[\int\right] ; y=[\mathrm{j}]$. Acute accents over vowels represent stressed syllables. I use the following abbreviations in glosses: 1, 2, 3 = first, second, third person; $\mathrm{AOR}=$ aorist; $\mathrm{ATTR}=$ attributive; $\mathrm{COP}=$ copula; HUM.PL $=$ human plural; IMP = imperative; $\mathrm{INCH}=$ inchoative; INS.NMLZ = instrument nominalization; INT.PST = intermediate past; $\mathrm{IPFV}=$ imperfective; $\mathrm{NC}=$ negative concord; $\mathrm{NEG}=$ negation; $\mathrm{NMLZ}=$ nominalizer; POSS = possessive; $\mathrm{Q}=$ question particle; $\mathrm{SG}=$ singular (for Motu data); $\mathrm{SR}=$ switch reference; STATIC = static prefix; SUBJ = subject (for Motu data); SUBJ.REL = subject relative; TOP = topic marker (for Motu data). In the presentation of data, I use * to indicate that a sentence is syntactically ill-formed, and \# to indicate that a sentence is grammatical, but unacceptable in the given context. 

(4) t'é:liwhu delkáykayi? k'é?i da?mó?mo?
t'e:liwhu de-Pil-kaykay-i? k'-e?-i da?mo?mo?
man NMLZ-ATTR-tall-ATTR 3-COP-IPFV woman
delkáykayî́xs k'á?aš
de-Pil-kaykay-î-ěs k'-e?-a?-š
NMLZ-ATTR-tall-ATTR-NEG 3-COP-AOR-SR

'The man is taller than the woman.'

(Literally: 'The man is tall, the woman is not tall.')

I propose that this pattern of cross-linguistic variation can be captured by positing variation in the lexical semantics of gradable predicates. Specifically, gradable predicates in Washo lack a degree variable. Instead, they are contextsensitive vague predicates as in (5).

(5) $\llbracket$ tall $_{\text {Washo }} \rrbracket^{c}=\lambda x \cdot x$ counts as tall in $c$

The semantics in (5) contains no measure function, and no degree variable at all. Given the hypothesis that the function of degree morphology is to bind a degree variable, this analysis for Washo explains its absence in this language. In other words, the variation observed between English and Washo in the inventory of functional categories is due to variation in the lexical semantics of gradable predicates, assuming a semantics in (1) for English.

This analysis echoes that of Beck, Krasikova, et al. (2009) for Motu, an Austronesian language of Papua New Guinea. Motu also makes use of conjoined comparison, and lacks other degree constructions as well. An example of a conjoined comparison in Motu can be seen in (6).

(6) Mary na lata, to Frank na kwadōgi.

Mary TOP tall, but Frank TOP short

'Mary is taller than Frank.' ～(MOTU; Beck, Krasikova, et al. 2009, p. 3)

Beck, Krasikova, et al. likewise locate the source of this gap in a parameter of cross-linguistic variation in the lexical semantics of gradable predicates. Their Degree Semantics Parameter (DSP) is given in (7): 
Degree semantics and cross-linguistic variation

(7) Degree Semantics Parameter (DSP):

A language $\{$ does/does not $\}$ have gradable predicates (type $\langle d,\langle e, t\rangle\rangle$ and related), i.e., lexical items that introduce degree arguments.

(Beck, Krasikova, et al. 2009, p. 19)

There are two theoretical issues at stake regarding the DSP that I aim to address in this paper. The first is whether we have the right kind of empirical support that leads us to conclude that the DSP, or something like it, is an active parameter of variation that needs to find a place in semantic theory. In their cross-linguistic study, Beck, Krasikova, et al. in fact proposed three distinct parameters to account for the variation observed between the 14 languages they investigated. The parameter that has received the most attention in the literature is their Degree Abstraction Parameter (DAP), which was first proposed by Beck, Oda \& Sugisaki (2004):

(8) Degree Abstraction Parameter (DAP):

A language \{does/does not have binding of degree variables in the syntax.

(Beck, Oda \& Sugisaki 2004, p. 325)

The DAP is supposed to account for the languages in their study that fail to show negative island effects in comparatives or scope interactions between comparatives and other operators such as modals (these languages are Chinese, Japanese, Mooré, Samoan, and Yorùbá). Such languages would have a positive setting of DSP, but a negative setting of DAP. The DAP, however, has been the subject of much recent scrutiny, particularly on the basis of more data from Japanese (Hayashishita 2009, Kennedy 2007a, Shimoyama 2012, Sudo 2014). For instance, Shimoyama (2012) provides evidence from certain clausal comparatives that display island sensitivities, suggesting that degree abstraction is at work in Japanese after all, thus questioning whether the DAP is the right way to account for the differences between English and Japanese.

While I do not intend to rehearse the arguments for and against the DAP as discussed by these authors, I bring up this issue in order to highlight the contribution of the Washo data to the theoretical debate surrounding Beck, Krasikova, et al.'s proposals. The fact that the validity of the DAP has been called into question (at least for the analysis of Japanese) indicates that their proposed parameters may not hold up to deeper cross-linguistic scrutiny. This point is particularly pressing for the evaluation of the DSP, since in Beck, Krasikova, et al.'s survey of 14 languages, Motu was the sole language that motivated positing the DSP as a parameter of cross-linguistic variation. 
No other languages, to my knowledge, have since been claimed to have the negative setting of this parameter.

Second, it is not even clear to what extent the DSP makes the correct predictions for Motu in the first place. In the appendix of their paper, Beck, Krasikova, et al. observe that Motu speakers can make comparisons with differential measure phrases using an element glossed as 'exceed', as shown in (9), while Stassen (1985) offers the example in (10) with another verb glossed as 'exceed'.

(9) Mary na $2 \mathrm{~cm}$ ai Frank ena lata e hanaia.

Mary TOP $2 \mathrm{~cm}$ by Frank his height 3.SG.SUBJ exceed

'Mary is 2cm taller than Frank.' $\quad$ (MOTU; Beck, Krasikova, et al. 2009, p. 49)

(10) Una na namo, ina herea-ia that is good this exceeds

'This is better than that.'

(MOTU; Stassen 1985, p. 48)

Washo thus provides us with a testing ground for subjecting the DSP to further cross-linguistic scrutiny. Previewing what is to come, I will show that the Washo data indeed provide evidence that languages can systematically lack degree morphology, and I argue that this supports the view that the DSP is an active parameter of semantic variation.

This style of analysis for the Washo facts then raises questions about the nature of semantic variation across languages. Matthewson (2001) and von Fintel \& Matthewson (2008) argue that research in cross-linguistic semantics should proceed by taking a strong universalist stance of no variation as the null hypothesis, which should only be rejected once evidence from thorough investigation necessitates. In particular, Matthewson (2001) argues that parametric solutions to variation weaken the strong null hypothesis of no variation and that "they must be argued for on the basis of considerable empirical advantages” (p. 157). The DSP is such a parameter, under which languages can vary in quite a fundamental way, namely whether or not they have gradable predicates that introduce degree variables. This raises the question: can we do better? Is there a way to maintain a certain amount of uniformity in the semantics of gradable predicates and degree constructions cross-linguistically without making recourse to a parameter on possible meanings available to languages? 
Degree semantics and cross-linguistic variation

In the second part of this paper, I address this question by considering the alternative hypothesis that gradable predicates in both Washo and English are degreeless vague predicates. Such an analysis for English has been defended by Kamp (1975), Klein (1980, 1991), van Rooij (2011a,b), and Burnett (2014), among others. This view maintains uniformity at the level of the lexical semantics of gradable predicates across languages, but where English and Washo vary would be in terms of the sorts of other logical operations over different abstract metalanguage objects. Although I will show that this analysis can capture the differences between English and Washo, it does so at the expense of a unified analysis of degree constructions more generally. In this sense, the degree-based analysis in terms of the DSP captures the cross-linguistic variation in a much simpler way.

The remainder of the paper is structured as follows. In Section 2 I introduce the Washo data, and show that Washo lacks degree morphology of the sort found in English, including comparatives, superlatives, equatives, measure phrases, and degree adverbs. These findings are consistent with the hypothesis that this language instantiates the negative setting of the DSP. Then in Section 3 I take a step back and ask whether lexical variation is the right way to account for the cross-linguistic facts. In Section 4 I consider how a theory framed within the degree-free analysis for English would handle the cross-linguistic facts, largely drawing on van Rooij's recent analysis. I conclude in Section 5 by speculating on the nature of cross-linguistic variation in view of the analysis I propose, specifically with respect to the apparent absence of degrees in certain languages, and the bounds of cross-linguistic expressivity given such a gap.

\section{Gradation structures in a degreeless language}

In this section, I outline the landscape of 'degree' constructions and the interpretation of gradable predicates in Washo. The main claim is that Washo lacks any functional morphology that targets a degree variable. I argue that there is no comparative morpheme in conjoined comparisons, with evidence coming from crisp judgment effects, their incompatibility with absolutestandard predicates, and their obligatorily norm-related interpretation. I then show that Washo also lacks measure phrases, equatives, superlatives, and degree adverbs. This systematic gap in degree morphology is taken as evidence that gradable predicates in Washo lack a degree variable, and have a lexical semantics as in (11), repeated from above. The Washo facts thus 
provide new evidence for a parameter of semantic variation along the lines of the DSP proposed by Beck, Krasikova, et al. (2009).

(11) $\llbracket$ tall $_{\text {Washo }} \rrbracket^{c}=\lambda x \cdot x$ counts as tall in $c$

Before diving into the Washo constructions, I first briefly outline the morphosyntax of gradable predicates in this language. Lexical items naming gradable concepts have the morphosyntactic distribution of verbs. In (12a), yasay 'hot' is a monomorphemic verb stem that is inflected directly for aspect. ${ }^{5}$ In (12b), the stem -kaykay- 'tall' is flanked by the morphemes Pil-... -i?, both glossed as 'attributive', following Jacobsen (1964, 1980).

$$
\begin{aligned}
& \text { a. PitdíPyu yásayi gawguwilé:s } \\
& \text { Pit-di?yu yasay-i ge-wguwil-e:s } \\
& \text { INS.NMLz-fire hot-IPFV IMP-touch-NEG } \\
& \text { 'The stove is hot, don't touch it!' } \\
& \text { b. mé:hu Pilkáykayi?i } \\
& \text { me:hu Pil-kaykay-i?-i } \\
& \text { boy ATTR-tall-ATTR-IPFV } \\
& \text { 'The boy is tall.' }
\end{aligned}
$$

The set of predicates that must take the attributive ?il-...-i? morphology does not seem to be constrained by any semantic feature (e.g., dimensional vs. non-dimensional, absolute vs. relative). Rather, it seems to be a morpho(phono)logical issue: a subset of gradable predicate roots such as -kaykaycannot serve as verb stems on their own, and must be marked by iil-...-i? These are also the roots that can occur in their unreduplicated form in bipartite verb stems (see Jacobsen 1980 and Section 2.2 below).

Gradable predicates can also appear in a nominalized form, via the derivational prefix de- or $t^{\prime}$ - (depending on whether a verbal stem is consonantor vowel-initial, respectively). This prefix attaches outside the attributive morphology, if it is present in the non-nominalized form. When used predicatively, the nominalized form is accompanied by the copula verb -e?, which is where verbal agreement and aspectual morphology appear. In (13a), the

5 That is to say, the verb is marked with a final suffix that is obligatory in finite clauses. Following Jacobsen (1964), I gloss the suffixes $-i$ and $-a$ ? as 'imperfective' and 'aorist', respectively, though it is far from clear whether these suffixes carry any temporal/aspectual semantics. 
Degree semantics and cross-linguistic variation

monomorphemic verb stem yak'aš 'warm' is nominalized, while in (13b), a stem with attributive morphology is nominalized. ${ }^{6}$

$$
\begin{array}{ll}
\text { a. dírbe dayák’aš } & \text { k’éPi } \\
\text { diæbe de-yak’áš } & \text { k'-e?-i } \\
\text { sun NMLZ-warm } & \text { 3-COP-IPFV }
\end{array}
$$

'The sun is warm.'

b. mé:hu delkáykayi? k'é?i

merhu de-Pil-kaykay-i? k'-e?-i

boy NMLZ-ATTR-tall-ATTR 3-COP-IPFV

'The boy is tall.'

As far as I can tell, there is no semantic difference between scalar predicates when they appear as verbs or in a nominalized form, at least for the constructions to be discussed here. ${ }^{7}$ Going forward, these two forms of scalar predicates will be taken to have equivalent semantic interpretations. See Jacobsen $(1964,1996)$ and Bochnak (2013) for more details on Washo morphosyntax.

\subsection{Conjoined comparison as implicit comparison}

As I have already indicated, the main strategy for making comparisons in Washo is with conjoined comparison as in (4), repeated in (14). The comparison in (14) is based on a dimensional predicate (using the terminology of Bierwisch 1989), but this construction can also be used with non-dimensional, or evaluative, predicates, as in (15), and for amount comparison, as in (16). As these examples show, the predicate in the second clause is the same as the one in the first clause plus the negation suffix -eis, but a lexicalized antonym pair can also appear in this construction, as shown in (17).

6 The prefix $d e$-is phonetically realized as $d a$ - when the following vowel is $a$ or $o$. Other morphemes in the language also show this type of vowel harmony, including ge- 'imperative' in (12a).

7 In Washo generally, verbal predicates receive an episodic interpretation, while the corresponding nominalized forms receive a generic interpretation (Bochnak, Grinsell \& Yu 2011). 
(14) t'é:liwhu delkáykayi? k'éPi da?mó?mo?

t'elliwhu de-Pil-kaykay-i? k'-e?-i da?mo?mo?

man NMLZ-ATTR-tall-ATTR 3-COP-IPFV woman

delkáykayi?é:s k'áPaš

de-Pil-kaykay-i?-ess k'-e?-a?-š

NMLZ-ATTR-tall-ATTR-NEG 3-COP-AOR-SR

'The man is taller than the woman.'

(Literally: 'The man is tall, the woman is not tall.')

(15) dawp'áp'il delélegi? Mísgi?ánawi?i

dawp'ap'łl de-Pil-leleg-i? Mirgi-Payaw-i?-i

flower NMLZ-ATTR-red-ATTR look-good-ATTR-IPFV

delc'ác'imi? Mírgilánawi?é:saš

de-Pil-c'ac'im-i? Mirgi-Panaw-i?-e:s-a?-š

NMZL-ATTR-yellow-ATTR look-good-ATTR-NEG-AOR-SR

'The red flower is prettier than the yellow one.'

(Literally: 'The red flower is pretty, the yellow one isn't pretty.')

(16) Beverly t'é:k'e? t'árgim Rî́wi demuc'úc'una t'é:k'eya

Beverly t'e:k'e? t'argim ?-i?iw-i de-muc'uc'u-ya t'e:k'e?-ya

Beverly many pine nuts 3 -eat-IPFV NMLZ-sweet-NC many-NC

Pi?wé:sa?

?-i?iw-e:s-a?

3-eat-NEG-AOR

'Beverly ate more pine nuts than berries.'

(Literally: 'Beverly ate many pine nuts, she didn't eat many berries.')

(17) mé:hu delkáykayi? k'é?i šáwlamhu

me:hu de-?il-kaykay-i? k'-e?-i šawlamhu

boy NMLZ-ATTR-tall-ATTR 3-COP-IPFV girl

Pilkúškuši?aš

Pil-kuškuš-î-â-š

ATTR-short-ATTR-AOR-SR

'The boy is taller than the girl.'

(Literally: 'The boy is tall, the girl is short.') 
Degree semantics and cross-linguistic variation

No overt comparative morphology is present in this construction, and in fact there is no evidence that a covert comparative morpheme is present either. To argue for this point, I make use of the distinction between explicit versus implicit comparison. Kennedy (2007a), who borrows the terminology from Sapir (1944), defines these terms as follows:

a. Explicit comparison: establishes an ordering relation between objects $x$ and $y$ with respect to a gradable property $G$ using a morphosyntactic form whose conventional meaning has the consequence that the degree to which $x$ is $G$ exceeds the degree to which $y$ is $G$.

b. Implicit comparison: establishes an ordering between objects $x$ and $y$ with respect to a gradable property $G$ using the positive form by manipulating the context in such a way that the positive form is true of $x$ and false of $y$.

The key distinction between explicit versus implicit comparison is that the former makes use of dedicated morphology to express the comparison relation, while the latter uses only the positive unmarked form, and a comparison between the two objects is inferred. For instance, the English construction in (19a) contains special morphology that marks the gradable predicate, while the construction in (19b) makes use of the positive (unmarked) form of the gradable predicate, and the compared to phrase restricts the comparative class to only Amy and Betty (Kennedy 2007a, 2011, van Rooij 2011a).

(19) a. Amy is taller than Betty.

EXPLICIT COMPARISON

b. Compared to Betty, Amy is tall.

IMPLICIT COMPARISON

Two of Kennedy's tests for distinguishing explicit and implicit comparisons are whether they give rise to crisp judgment effects, and their (un)acceptability with absolute standard gradable predicates. ${ }^{8}$ Based on both of these tests, conjoined comparisons in Washo pattern like implicit comparison, indicating the absence of even a covert comparative morpheme.

Kennedy's first test for explicit versus implicit comparison has to do with whether the construction can be used in crisp judgment contexts (i.e., to make fine-grained distinctions between two individuals with respect to some gradable property). Since implicit comparisons are based on the positive form of a gradable predicate, their use should exhibit the same interpretational

8 Kennedy (2007a) also makes use of a third test: differential measure phrases, which are acceptable with explicit comparison only. Since Washo does not have a measure phrase construction at all, this test cannot be performed. 
features as the positive form more generally. One such feature of the positive form of vague gradable predicates is that it is subject to the Similarity Constraint in (20) (Klein 1980, Fara 2000, Kennedy 2011).

(20) Similarity Constraint: When $x$ and $y$ differ only to a very small degree in the property that a vague predicate $G$ is used to express, speakers are unable or unwilling to judge the proposition that $x$ is $G$ true and $y$ is $G$ false.

Given this constraint, it should therefore be impossible to use implicit comparisons in situations where two objects differ only slightly in the amount they hold a property. Explicit comparisons, meanwhile, only require a nonzero difference in degrees, and are thus acceptable in crisp judgment contexts.

Washo conjoined comparisons behave like implicit comparisons with respect to this test, as shown in (21).

(21) Context: comparing two ladders, where one is only slightly taller than the other.

$$
\begin{aligned}
& \text { \#wí:di? Pitmána delkáykayi? k'éPi wí:di? } \\
& \text { wi:di? Pitmana de-Pil-kaykay-i? k'-e?-i wi:di? } \\
& \text { this ladder NMLZ-ATTR-tall-ATTR 3-COP-IPFV this } \\
& \text { delkáykayi?é:s k’á?aš } \\
& \text { de-Pil-kaykay-î-ers k'-e?-â-š } \\
& \text { NMLZ-ATTR-tall-ATTR-NEG 3-COP-AOR-SR }
\end{aligned}
$$

Intended: 'This ladder is taller than that one.'

(Literally: 'This ladder is tall, that one is not tall.')

The failure of using this construction in the given context follows if there is no explicit comparative morpheme present, and both occurrences of the gradable predicates are interpreted as vague predicates. The anomaly of (21) arises because in the first clause, the speaker asserts that one ladder counts as tall, while in the second clause, the speaker asserts that the other ladder does not. That is, by using this construction, speakers are required to assert that a property holds of one object, and that its antonym holds of another object. Because vague predicates are subject to the Similarity Constraint, speakers are unwilling to accept the truth of both clauses simultaneously in this context. 
Degree semantics and cross-linguistic variation

Washo speakers can get around this restriction by adding modifiers such as wewš (roughly 'almost') or šemu (roughly 'really'). One such example of a comparison offered by a speaker in a crisp judgment context is given in (22), which involves wews. ${ }^{9}$

(22) Context: comparing two pine cones that differ minimally in size.

wídi? behézịaš lák’a? wírdi? t'íryeli? wéwši

wi:di? behezin-a?-š lak'a? wirdi? t'izyeli? wewš-i

this small-AOR-SR one this big almost-IPFV

'This one is bigger than that one.'

(Literally: 'This one is small, that one is almost big.')

Such examples are important for showing that Washo speakers do not have difficulty in perceiving small differences between objects, nor are they completely unable to make comparisons in such situations. Rather, whereas English makes expressing comparisons in crisp judgment contexts easy for its speakers (via -er comparatives), Washo does so at the expense of greater complexity, requiring speakers to use hedges like in (22).

The second test for explicit versus implicit comparison is their behavior with gradable predicates with absolute standards. Gradable predicates such as wet, dry, bent, straight, do not show the same type of context-sensitivity and vagueness of relative standard predicates like tall (Kennedy \& McNally 2005, Kennedy 2007b). The standards for evaluating the positive form are fixed to a maximum or minimum endpoint of a scale, regardless of context of utterance. ${ }^{10}$ It is this lack of context-sensitivity that renders implicit com-

9 While I do not offer a detailed analysis of these modifiers here, see Section 2.3 for some comments on šemu, and Beltrama \& Bochnak (To appear) and Bochnak (2013) for more detailed analysis.

10 Kennedy \& McNally (2005) note that there are relative uses of absolute standard predicates, in which case they behave like predicates like tall in the relevant respects. Under this use, we would expect implicit comparisons to be acceptable. A reviewer offers the following example:

(i) My glass is empty, compared to your glass (your glass is full of beer and mine only has a small amount!)

Likewise, in their relative use, these adjectives also readily accept modification by very, which is normally restricted to relative gradable predicates (though see Syrett (2007) and $\mathrm{McNabb}$ (2012b) for corpus and experimental data showing that a more nuanced analysis is necessary).

(ii) The restaurant is very empty tonight (compared to a normal Friday). 
parisons infelicitous with absolute standard predicates. In fact, a conjoined comparison with absolute standard predicates will always be false, except in the limiting cases where one object holds the property to the maximum or minimum value. Explicit comparisons, however, are acceptable since they only require a non-zero difference in the amount two objects hold the property. This distinction in English is illustrated in (23).

\section{(23) Context: Rod A: $\longrightarrow \operatorname{Rod~B:}$}

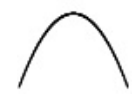

a. Rod B is more bent than $\operatorname{rod} \mathrm{A}$.

b. \#Compared to $\operatorname{rod} \mathrm{A}, \operatorname{rod} \mathrm{B}$ is bent.

Conjoined comparisons in Washo once again behave like implicit comparisons with respect to this test. This is illustrated in (24) with the same context as (23), where several combinations of both minimum-standard Pilk'únk'uni? 'bent', maximum-standard Pilšíšsibi? 'straight', and their negations, are attempted.

(24) Context: same as (23)
a. \#wírdi? Pilk'únk'uni?aš
wírdi? Pilší:šibi?i

wirdi? ?il-k'unk'un-i?-a?-š

wirdi? Pil-šisšib-i?-i

this ATTR-bent-ATTR-AOR-SR this ATTR-straight-ATTR-IPFV

Intended: 'This one is more bent than that one.'

(Literally: 'This one is bent, that one is straight.')

b.\#wí:di? Pilk'únk'uni?i wírdi? Pilk'únk'uni?é:saš

wirdi? Pil-k'unk'un-i?-i wirdi? Pil-k'unk'un-i?-ers-a?-š

this ATTR-bent-ATTR-IPFV this ATTR-bent-ATTR-NEG-AOR-SR

Intended: 'This one is more bent than that one.'

(Literally: 'This one is bent, that one is not bent.')
c. \#wírdi? Pilší:šibi?i wírdi?
wirdi? Pil-šisšib-i?-i wirdi?
this ATTR-straight-ATTR-IPFV this
Pilšíššibilé:saš
Pil-ši:šib-î-e:s-a?-š
ATTR-straight-ATTR-NEG-AOR-SR

Intended: 'This one is more bent than that one.'

(Literally: 'This one is straight, that one is not straight.') 
Degree semantics and cross-linguistic variation

The form of the conjoined comparison requires the speaker to assert that one of the properties Pilšíišibi? 'straight' or Pilk'únk'uni?ess 'not bent' holds of one of the rods, which is simply false in the context in (24).

As before, Washo speakers can get around this restriction by adding modifiers, as in (25).

(25) Context: same as (23)

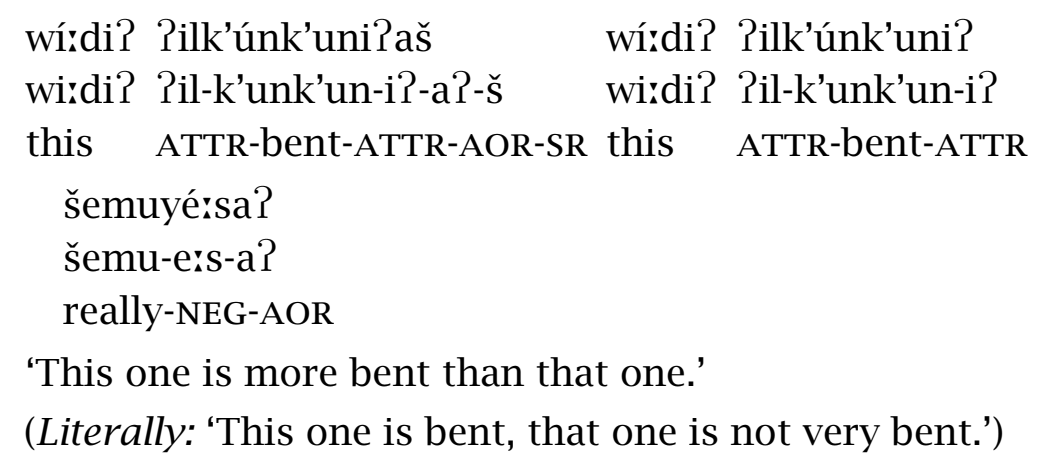

'This one is more bent than that one.'

(Literally: 'This one is bent, that one is not very bent.')

In sum, based on Kennedy's (2007a) tests, conjoined comparison in Washo is implicit comparison. This means that there is no evidence even for a covert comparative morpheme at work in these constructions.

Given that conjoined comparisons do not contain a comparative morpheme, together with the semantics for gradable predicates I propose for Washo in (5), the truth conditions for the conjoined comparison in (26) can be stated informally as in (27).

$$
\begin{aligned}
& \text { t'é:liwhu delkáykayi? k'éPi da?mó?mo? } \\
& \text { t'e:liwhu de-Pil-kaykay-i? k'-e?-i da?mo?mo? } \\
& \text { man NMLZ-ATTR-tall-ATTR 3-COP-IPFV woman } \\
& \begin{array}{ll}
\text { delkáykayiié:s } & \text { k'áPaš } \\
\text { de-Pil-kaykay-î-e:s } & \text { k'-e?-a?-šs } \\
\text { NMLZ-ATTR-tall-ATTR-NEG } & \text { 3-COP-AOR-SR }
\end{array}
\end{aligned}
$$

'The man is taller than the woman.'

(Literally: 'The man is tall, the woman is not tall.')

(27) $\llbracket(26) \rrbracket^{c}=1$ iff the man counts as tall, and the woman does not count as tall in $c$

The truth conditions in (27) are simply the conjunction of those of the two conjoined clauses. Note that these truth conditions entail that the man 
is taller than the woman, given the Consistency Constraints in (28), which are independently necessary to constrain admissible delineations over the domain of discourse (Klein 1980, 1991, Kennedy 2011, van Rooij 2011a).

\section{Consistency Constraints:}

a. For any positive form gradable predicate $G$ and objects $x$ and $y$, if there is a context $c$ such that $G$ holds of $x$ but not of $y$ in $c$, then for any $c^{\prime}$ such that $G$ holds of $y$ in $c^{\prime}$, then $G$ also holds of $x$ in $c^{\prime}$.

b. For any positive form gradable predicate $G$ and objects $x, y$ and for any context $c$, if $G$ holds of $x$ but not of $y$ in $c$, then $x$ exceeds $y$ relative to the scalar concept encoded by $G$.

The second of these constraints is crucial for the comparison interpretation of conjoined structures. Specfically, if the speaker is committed to the truth of t'é:liwhu delkáykayi? k'éri 'the man is tall', and to the truth of da?mó?mo? delkáykayi?é:s k'á?aš 'the woman is not tall', then it follows from (28) that the speaker is also committed to the proposition that the man exceeds the woman in height. That is, while a comparison between the two individuals is not asserted by the speaker of (26), it is entailed by the truth conditions in $(27){ }^{11}$

\subsection{Norm-relatedness in conjoined comparisons and beyond}

A welcome outcome of this analysis is that it captures the fact that conjoined comparisons in Washo always receive a norm-related interpretation. That is, the subject of each gradable predicate must hold the relevant property in an absolute sense in order for the comparison to be felicitously uttered. A case in point is (29), where the conjoined comparison in (26) is judged unacceptable in the described context, where both individuals clearly do not count as tall.

11 A reviewer asks whether it is crucial that the truth conditions in (27) make use of a single comparison class shared by both conjuncts. This is in fact crucial for the comparison entailment to go through via the Consistency Constraints. Otherwise, if the compared objects do not belong to the same comparison class, the inference that one exceeds the other in height may not be valid. This seems correct to me, since in general a conjunction of two sentences need not be understood as a comparison. 
Degree semantics and cross-linguistic variation

(29) Context: Comparing a man who is five feet tall and a woman who is four and a half feet tall (i.e., both clearly fall under the negative extension of tall)

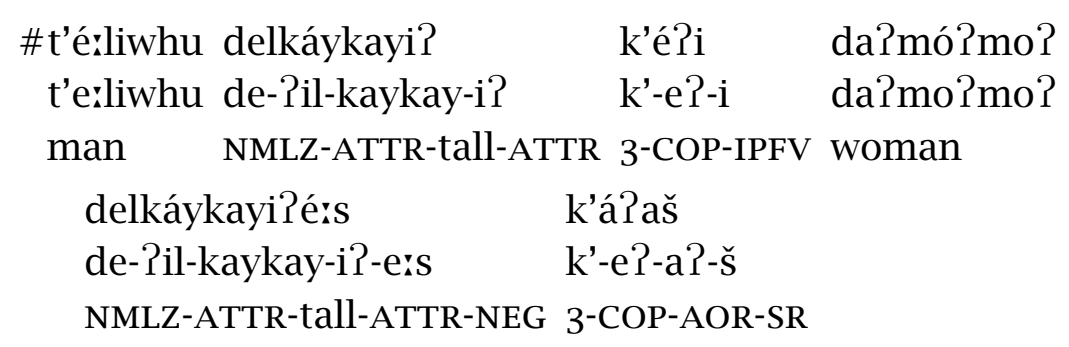

Intended: 'The man is taller than the woman.'

Under the proposed analysis, the conjoined comparison is simply false in the context in (29). Furthermore, the facts related to crisp judgment contexts and absolute standard predicates fall out as special cases of the more general property of conjoined comparisons that they are obligatorily norm-related.

I am not in a position at this point to state that obligatory norm-relatedness is an essential property of conjoined comparisons cross-linguistically. ${ }^{12}$ For instance, Marsack (1975) offers the following conjoined comparison in Samoan, and notes, "Even in the case of giant vessels like the Queen Mary and the Aquitania this construction would be used. To indicate that the 85,000 ton Queen Mary is bigger than the 45,00o ton Aquitania, a Samoan of the old school would say [(30)]" (Marsack 1975, p. 66, cited in Kennedy 2011). ${ }^{13}$

(30) Ua tele le Queen Mary, ua la'itiiti le Aquitania is big the Queen Mary is small the Aquitania

'The Queen Mary is bigger than the Aquitania.'

(SAMOAN; Marsack 1975)

These anecdotal comments suggest that the comparison in (30) does not obligatorily receive a norm-related interpretation, since it is reasonable to assume that both ships count as big in an absolute sense. Of course, such comments do not constitute a semantic analysis of the construction. For instance, one might say that the relevant comparison class here is a set of large cruise liners, in which case the Aquitania might count as small, and

12 Thanks to Amy Rose Deal and an anonymous reviewer for pushing me to be explicit on this point.

13 In this quote, Marsack is highlighting the fact that younger generations of Samoan speakers do not accept comparisons like (30) and now use a comparison strategy that looks more like an explicit comparison; see Hohaus (2012). 
we could say that (30) is norm-related after all. More research is necessary on the semantic properties of conjoined comparison languages to determine whether there are any generalizations to be made in this respect.

Relatedly, further note that obligatory norm-relatedness is not a necessary property of implicit comparisons in general. In fact, as pointed out by Sawada (2009), implicit comparisons like (31) in English (and Japanese) actually carry the implicature that the two individuals are not tall (either short, or borderline cases).

(31) Compared to Betty, Amy is tall.

(Implicature: neither actually count as tall.)

The relevant implicature can be derived in Gricean terms as follows. If the speaker of (31) was committed to the truth of Amy is tall, then s/he should have said so, without hedging with the compared to phrase. But the speaker chose to use (31) instead, leading the hearer to infer that the speaker does not believe Amy is tall is true. Crucially, the implicature arises because of the existence of (31) as a competing construction to a plain, unmodified assertion of Amy is tall in English. In Washo, the conjoined comparison has no extra morphology, even a compared to phrase that flags the construction as a comparison, so no such implicature arises.

Norm-relatedness is also not a property of English explicit comparisons. The sentence in (32) does not entail that either the standard or target of comparison count as tall in an absolute sense.

(32) Amy is taller than Betty.

a. $\rightarrow$ Betty is tall.

b. $\rightarrow$ Amy is tall.

On the degree-based analysis for English, the lack of entailment to the positive form is captured by the fact that the comparative morpheme and a null degree operator that contributes the absolute interpretation (pos) are in complementary distribution. When the degree argument of the gradable predicate is not bound by the comparative or other degree morphology, the null morpheme pos enters the derivation, binding the open degree argument and contributing the absolute semantics. Since it is pos that is responsible for the norm-related interpretation, and it is not present in comparatives like (32), the lack of entailments to the positive form is predicted. 
Degree semantics and cross-linguistic variation

Under my analysis for Washo, norm-relatedness comes directly from the vague predicate semantics in (11). Now, if one were inclined to defend a degree-based analysis of Washo gradable predicates, how would such an account deal with the conjoined comparison and norm-relatedness facts? Given that there is no evidence for a comparative morpheme in the language, one would have to say that there is a null pos morpheme that binds the degree argument and introduces the contextual standard for each gradable predicate in conjoined comparisons. This analysis thus predicts norm-relatedness in conjoined comparisons, and further maintains a uniform denotation for gradable predicates cross-linguistically, contra my proposal.

Under such a view, we could propose that pos is realized in Washo as the attributive morphology ill-...-i? that flanks many gradable predicates, and which I so far have ignored. The composition of the gradable predicate Pil-kaykay-i? 'tall' would be derived as in (35) by combining -kaykay-, a gradable predicate containing a degree argument as in (33), with the attributive morphology contributing the semantics of pos, as in (34):

（33） $\llbracket-k a y k a y-\rrbracket=\lambda d \lambda x \cdot \operatorname{HEIGHT}(x) \geq d$

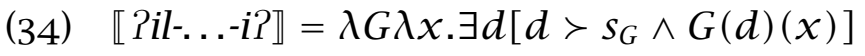

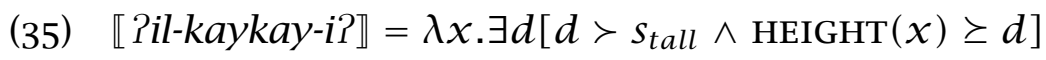

Under this proposal, Washo would be a remarkable language from the point of view of degree semantics for at least two reasons. First, it would provide us with an example of a language that has a single-membered set of degree morphemes at its disposal, in contrast to languages like English that have many more. ${ }^{14}$ Second, Washo would be a language that has an overt exponent of the pos morpheme, addressing a long-standing worry of opponents of the degree analysis that the overt manifestation of this morpheme is absent cross-linguistically. I maintain, however, that this analysis of Washo is undesirable.

First, as I have already pointed out, there are many verbal stems in Washo that do not compose with the attributive morphology, and nevertheless receive a norm-related interpretation. Rather, these verb stems compose directly with verbal morphology without first combining with the attributive affixes. The set of gradable predicates that do not require attributive morphology appears to be random, and not determined by some semantic

14 I discuss the absence of other degree morphemes in Washo in Section 2.3 below. 
parameter (e.g., relative versus absolute standard predicates, or dimensional versus non-dimensional predicates). ${ }^{15}$ Thus, under this alternative account, it would simply have to be stipulated that some gradable predicates do not combine with pos, or combine with a null version of pos that contributes the norm-related semantics.

Second, even the gradable predicates that do combine with attributive morphology receive a norm-related interpretation in environments where the attributive morphology is not present. An environment where the attributive morphology does not occur is in bipartite verb stem constructions, which are formed by the concatenation of two bound morphemes to form a complex verbal stem (Jacobsen 1980, Bochnak \& Rhomieux 2013). For instance, the root -ilp'il- 'blue' in its predicative use is in a reduplicated form, flanked by the attributive morphemes, as in (36), while it appears as the second element of a bipartite stem in (37).

(36) Pilp’ílp'ili?i

Pil-p'ilp'il-i?-i

ATTR-blue-ATTR-IPFV

'It is blue.'

(37) tugílp'ili

tug-ilp'il-i

eye-blue-IPFV

'He has blue eyes.'/'He is blue-eyed.' (Jacobsen 1964, p. 109)

The semantics of the individual roots that make up bipartite stems can be difficult to test, since many bipartite stems have somewhat idiomatic meanings that are not fully compositional. However, an example relevant for our purposes comes from the bipartite verb form in (38), where the bipartite verb means 'to iron', and includes the root -išsib- 'straight' (compare with (39), where this root appears with attributive morphology).

15 Roots that must combine with attributive morphology in their reduplicated form include -hawhaw- 'light' (weight), -kaykay- 'tall', -k'unk'un- 'bent', -kuškuš- 'short/stumpy', -leleg- 'red', -p'ilp'il- 'blue', -popošs- 'gray', -šisšib- 'straight', -šiššš- 'heavy', -teteb- 'fat', -witwid- 'hard/stiff'. Roots that do not require attributive morphology include Panaw 'nice/good', ihuk' 'dry', metu? 'cold', mi:p'il 'full', mosod 'wet', muc'uc'u 'sweet', Mile 'old', yak'aš 'warm', yasay 'hot'. These are not exhaustive lists, but they serve to make the point that semantic class does not predict whether a root requires the attributive morphology. 
Degree semantics and cross-linguistic variation

(38) didé:šibi

di-de-i:šib-i

1-with.instrument-straight-IPFV

'I'm ironing it.'

(39) Rilší:šibi?i

Pil-šiššib-i?-i

ATTR-straight-ATTR-IPFV

'It is straight.'

Evidence that the verb in (38) contains the norm-related interpretation of the root -i:šib- 'straight' comes from the unacceptability of cases like (40). If the root -i:šib- has a norm-related semantics, then a denial that the scalar predicate holds should lead to a contradiction. Speakers do in fact judge such cases unacceptable, which is shown in (40).

(40) Context: I was ironing my clothes, but I couldn't get all the wrinkles out. The clothes just aren't getting straight.

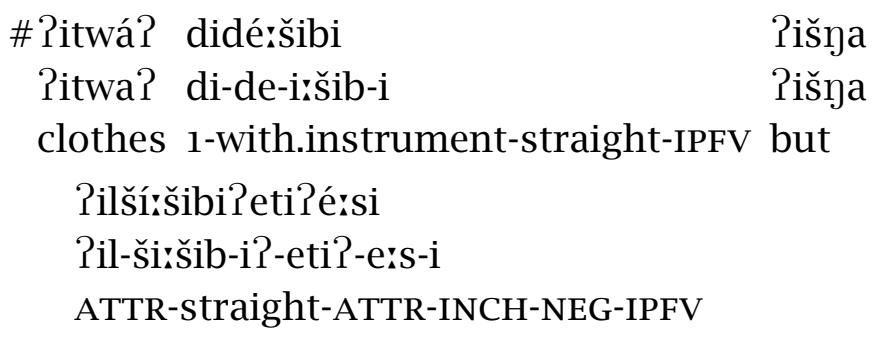

Intended: 'I ironed the clothes, but they're not straight.'

I take this as evidence that norm-relatedness is encoded directly in the roots of gradable predicates, and is not a contribution of the attributive morphology, or some other silent morpheme that introduces the contextual standard. I therefore suggest that the attributive morphology is semantically vacuous (either denoting the identity function on gradable predicates, or invisible to semantic composition), and appears with scalar roots that for morphophonological reasons cannot function as verbal stems on their own. Such roots must combine with some other morphology, either an initial element of a bipartite stem or the attributive morphology, to appear in a verbal construction.

In sum, these last two subsections have shown that there is no evidence for a comparative morpheme in Washo conjoined comparisons. Furthermore, 
gradable predicates always receive a norm-related interpretation in this construction, and also in bipartite verb constructions. These facts are consistent with the hypothesis that gradable predicates in Washo do not contain a degree variable, and in fact fall out quite elegantly from the analysis proposed here. Under this proposal, there is also no need to posit a pos morpheme. ${ }^{16}$ In the next subsection, I show that Washo not only lacks a comparative morpheme, but also other degree morphology such as measure phrases, equatives, superlatives, and degree adverbs, providing further evidence for my analysis.

\subsection{The absence of other degree constructions}

Measure phrases like five feet in five feet tall are members of the class of degree morphemes in a language like English. In Kennedy \& McNally's (2005) account, measure phrases denote functions from gradable adjective meanings to predicates of individuals by binding the degree variable and placing a restriction on the value that degree. Elsewhere in the literature, they are taken to denote degrees, or sets of degrees or intervals (von Stechow 1984, Heim 2001, Schwarzschild 2002, 2005, Svenonius \& Kennedy 2006). The common component of this style of analysis is that the measure phrase targets a degree variable associated with the gradable predicate. Thus, if gradable predicates in a given language do not contain degree variables, we expect that their combination with measure phrases will not be licensed.

This prediction is upheld in Washo. As shown in (41), measure phrases cannot appear as modifiers of gradable predicates.

$\begin{array}{ll}\text { (41) * hélme? múPc'im dewgálisi? } & \text { Míleyi } \\ \text { helme? muPc'im de-w-galis-i? } & \text { Mile-i } \\ \text { three ten NMLZ-STATIC-winter-ATTR old-IPFV } \\ \text { Intended: 'He is thirty years old.' }\end{array}$

The intended meaning of (41) can be expressed in Washo by using the construction in (42). In this case, a putative measure phrase occurs in a copula construction, with no gradable predicate present in the sentence.

16 An alternative would be to view pos instead as a type-shifting rule that binds the degree variable and provides the norm-related semantics. For example, under Grano's (2012) analysis, type-shifting pos applies at the AP level, transforming a $\langle d,\langle e, t\rangle\rangle$ relation into a predicate that can then combine with its subject. The same arguments from the bipartite verb stem data can be used against positing this sort of type-shifting pos at the AP level for Washo. 
Degree semantics and cross-linguistic variation

$(42)$
hélme? múPc'im dewgálisi?
k'éPi
helme? mu?c'im de-w-galis-i?
k'-e?-i
three ten NMLZ-STATIC-winter-ATTR 3-COP-IPFV
'He is thirty years old.'

Given that Washo does have numerals, perhaps a more accurate and enlightening generalization is that Washo does not lexicalize units of measurement. That is, Washo does not have any items such as foot, meter, pound, etc., that lexicalize conventionalized units of measurement along a dimension.

It is of course well known that the inventory and behavior of measure phrases cross-linguistically is quite idiosyncratic (see e.g., Schwarzschild 2005). Many languages, for instance, disallow measure phrases in combination with the absolute form of gradable predicates, but nevertheless allow measure phrases with (explicit) comparatives, where they receive a differential interpretation (Schwarzschild 2005, Grano \& Kennedy 2012). Since Washo lacks explicit comparisons, it follows that differential measure phrases are also not found in this language. Additionally, measure phrases are also commonly found with certain prepositional phrases (Zwarts 1997, Zwarts \& Winter 2000). Attempts to elicit such structures in Washo, even with nonce measure phrases (e.g., Beverly is three people ahead of me in line), have met with some difficulty, and more thorough investigation must be left to future research.

In sum, the combination of measure phrases with gradable predicates in Washo is ungrammatical, and in fact true measure phrases seem not to exist at all in the language. This fact is consistent with, and expected under, the hypothesis that gradable predicates in Washo do not come equipped with degree variables.

Washo furthermore lacks any dedicated equative or superlative morphology. This is actually expected, given the lack of a comparative morpheme in the language. Typological work has shown there is a one-way implication such that there appear to be no languages that we know of that have dedicated equative or superlative morphemes, but lack a comparative morpheme (Bobaljik 2012, Stassen 1985). ${ }^{17}$ Translations of English equatives typically involve the comitative suffix -hak'a (roughly 'with'), which is used more generally for NP coordination; see (43)-(45).

17 It should be noted that this typological claim about equatives is based on a smaller sample. See Haspelmath \& Buchholz (1998) for a typological survey of equative and similative constructions, and Rett (2013) for a formal analysis. 
M. Ryan Bochnak

(43) t'é:liwhuhak'a šáwlamhu t'é:k'e? wewgíPiši?i

t'e:liwhu-hak'a šawlamhu t'exk'e? w-wgi?iš-i?-i

man-with girl much STATIC-measure-ATTR-IPFV

'The man and the girl are heavy.'

(Prompt: 'The man is as heavy as the girl.')

(44) mé:hu šáwlamhuhak’a wagayáy?-i

me:hu šawlamhu-hak'a wagayay?-i

boy girl-with talk-IPFV

'The boy and the girl are talking.'/'The boy is speaking with the girl.'

(45) Puyábihak’a demubáibìl

Puyabi-hak'a demuba:bil

salt-with pepper

'salt and pepper'

Similarly, there is no dedicated superlative morphology. Washo makes use of a cross-linguistically common strategy (see Bobaljik 2012), whereby the regular comparison construction is used with a universal quantifier as the standard of comparison. The sentence in (46), intended as a superlative, uses conjoined comparison, where the subject of the second clause is millew 'everyone'.

(46) Context: My son is the tallest in his class.

$\begin{array}{lll}\text { diyám } & \text { Pilkáykayi?i } & \text { míPlew } \\ \text { diyam } & \text { Pil-kaykay-i?-i } & \text { mi?le?-w } \\ \text { l.POSS-son } & \text { ATTR-tall-ATTR-IPFV } & \text { everything-HUM.PL } \\ \text { PilkáykayiPé:si } & \\ \text { Pil-kaykay-i?-e:s-i } & \\ \text { ATTR-tall-ATTR-NEG-IPFV } & \end{array}$

'My son is tall, everyone is not tall.'

Finally, I claim that Washo also lacks any degree adverbs along the lines of very or completely in English. I only sketch an outline of the arguments here; see Beltrama \& Bochnak (To appear) and Bochnak (2012, 2013) for more detailed arguments, and analyses of the relevant phenomena.

In English, degree adverbs are sensitive to the scale structure of a gradable predicate and/or whether the gradable predicate is associated with a relative 
Degree semantics and cross-linguistic variation

or absolute standard (Rotstein \& Winter 2004, Kennedy \& McNally 2005). For instance, very modifies gradable predicates with relative standards, which usually coincides with a scale structure lacking maximum and minimum elements, while completely only modifies predicates with upper-closed scales, whose set of degrees includes a maximum value. The contrasts in (47) are thus taken as evidence that degree adverbs track distinctions in the sets of degrees included in the scales associated with gradable predicates.

(47) a. The bottle is very tall/\#closed.

b. The bottle is completely closed/\#tall.

A promising candidate for a degree adverb in Washo is the modifier šemu, which often translated by speakers as 'very'. However, the distribution of šemu is much wider than English very. As shown in (48)-(50), šemu can modify relative and absolute (maximum and minimum) standard gradable predicates alike. $^{18}$

$\begin{array}{ll}\text { Pilkáykayi? } & \text { šému } \\ \text { Pil-kaykay-i? } & \text { šemu } \\ \text { ATTR-tall-ATTR } & \text { ŠEMU } \\ \text { 'very tall' } & \end{array}$

RELATIVE STANDARD

(49) Rilší:šibi? šému

Pil-šišsib-i? Šemu

ATTR-straight-ATTR ŠEMU

'really straight'

UPPER-CLOSED SCALE

(50) Pilk'únk'uni? šému

Pil-k'unk'un-i? šemu

ATTR-bent-ATTR ŠEMU

'really bent'

LOWER-CLOSED SCALE

In fact, šemu is not limited to modifying gradable predicates. It can also be used to modify verbs and nouns more generally, and even numerals, as shown in (51)-(54). Such behavior would be surprising if šemu were a true degree modifier, assuming verbs and nouns generally do not lexicalize degree variables. ${ }^{19}$ The example in (54) is particularly revealing here, for even if we

18 In cases where English very is dispreferred, I use really in the free translations.

19 While it might be plausible to claim that a verb like yaha 'hurt' lexicalizes a scale of intensity that can be targeted in degree constructions (cf. English My left hand hurts more than my 
were to grant that in the other examples, šemu is targeting a lexicalized scale of closeness to a prototype, such an explanation could not be extended to (54).
lák’a? lá:du
yáha šémuyi
lak'a? le-a:du yaha šemu-i
one 1.POSs-hand hurt ŠEMU-IPFV

'One of my hands really hurts.'

(52) t'é:liwhu dókto šému k'éPi

t'e:liwhu dokto šemu k'-e?-i

man doctor ŠEMU 3-COP-IPFV

'The man is a real doctor.'

(Speaker's comment: "It means he's not a quack!")

(53) lélim šému

lelim šemu

night ŠEMU

'middle of the night' or 'really dark'

(54) dubáldi? šému hé:š Tíîwi

dubaldi? šemu he:š P-i?iw-i

five ŠEMU Q 3-eat-IPFV

'Did he eat exactly five (apples)?'

Such evidence has led Beltrama \& Bochnak (To appear) and Bochnak $(2012,2013)$ to propose that šemu universally quantifies over a contextual parameter setting that affects the interpretation of the elements it modifies. This general idea involving universal quantification over contexts is quite similar in spirit to the analyses offered by Barker (2002) and Williamson (1999) for the English modifier definitely, and McNabb (2012a) for Hebrew mamaš 'really'. In Barker's approach, John is definitely tall is true in a world $c \in C$ (a member of the context set $C$ ) if John counts as tall in $c$ and there is no other $c^{\prime} \in C$ in which John's height is the same but he does not count as tall in $c^{\prime}{ }^{20}$ For Williamson, definitely applies to a proposition (set of worlds),

right one, My left hand hurts a lot), such an explanation cannot be extended to the rest of the examples in (52)-(54).

20 Interestingly, Barker's analysis is intended to capture the interpretation of definitely with relative gradable adjectives like tall, and consequently his analysis is degree-based. His 
Degree semantics and cross-linguistic variation

and returns a proposition that is true in all worlds accessible from the actual world, according to some accessibility relation. Similarly, McNabb proposes that the Hebrew modifier mamaš 'really' applies to a property and states that the property holds of an individual in all relevant contexts of evaluation.

In sum, the wide distribution of šemu leads to the conclusion that it is not a true degree adverb. This finding provides further evidence that Washo lacks degree morphology, consistent with the hypothesis that gradable predicates in this language do not contain degree variables. Of course, it is difficult to definitively prove the non-existence of some element: we always open ourselves up to the criticism that maybe we haven't looked hard enough. Nevertheless, after looking in all the usual places where we tend to find degree constructions cross-linguistically, we have come up empty-handed in our search for them in Washo.

\subsection{A brief note on scale structure and degrees}

One of the merits of the degree analysis of gradable predicates is that it can easily capture the behavior of relative versus absolute standard predicates by analyzing scale structure as consisting, in part, of a set of degrees (Kennedy \& McNally 2005, Kennedy 2007b). The distribution of degree modifiers can then be accounted for by making reference to scale structure. For example, completely only modifies those adjectives whose scale consists of a set of degrees that includes a maximum value, ruling out \#completely tall, while ruling in completely full. It appears, then, that a welcome side-effect of the present analysis for Washo is the lack of scale structure effects with šemu.

However, it would be wrong to conclude that scale structure distinctions are completely neutralized in this language. Indeed, as observed in Section 2.1, gradable predicates with absolute standards are unacceptable in conjoined comparisons. The relative/absolute distinction must therefore be at work in this language, despite the claim that gradable predicates in Washo make no use of degree variables.

analysis, though, should be made more general, given that definitely regularly modifies other predicates as well (e.g., It's definitely raining, He is definitely a doctor/a champion/Italian), which makes definitely look a lot like šemu with respect to cross-categorial modification. Lassiter (2011) provides an update of Barker's analysis for definitely in terms of probabilities. This move aims to reconcile the fact that definitely leads to higher-order vagueness, whereas universal quantification is not vague. 
Such a conclusion provides support for recent research that argues that the relative/absolute distinction is not degree-based after all (Burnett 2014, Gumiel-Molina, Moreno-Quibén \& Pérez-Jiménez To appear, McNally 2011, Toledo \& Sassoon 2011). For instance, McNally (2011) proposes that relative predicates are based on classification by similarity, whereas absolute predicates are based on classification by rule. Similarity-based classification involves comparing an individual and how it instantiates a property with other individuals and how they instantiate that property. For an object to count as tall, it needs to be compared to other individuals, and be close enough to exemplars that also count as tall in a context. This type of classification requires only a partial match, which accounts for the vagueness of relative standard predicates. By contrast, rule-based classification involves comparing an individual to an abstract representation of what counts as instantiating the relevant property. For example, to decide whether an object counts as full, we only need to know how much of its volume is occupied, and whether that amount is total or not. This type of classification requires a strict matching between representations, which is why rule-based classification is absolute. Toledo \& Sassoon (2011), meanwhile, argue that relative standard predicates involve comparison between individuals with respect to that property, while absolute standard predicates involve comparison within the same individual at distinct stages or worlds.

Although the accounts for the relative/absolute distinction without degrees differ in detail, what they have in common is that they involve functional cognitive processes of classification, which seem much less plausibly to be subject to cross-linguistic variation. While it may be the case that English and other degree-based languages might encode the relative/absolute distinction in scale structure (since they makes use of degrees independently of this distinction), what this line of research has revealed is that recourse to degrees is not necessary to account for it. Thus, the fact that we observe apparent scale structure effects in certain corners of Washo grammar should not be taken as evidence in favor of a degree-based analysis after all.

\subsection{Summary}

In this section, I have argued that Washo lacks the functional category of morphemes that target degree variables, including comparative, equative, and superlative morphology, as well as measure phrases and degree adverbs. This systematic gap is what is predicted for languages that instantiate the 
Degree semantics and cross-linguistic variation

negative setting of the DSP, and provides evidence for the parametric nature of the variation observed. We have thus found even more solid evidence that languages can vary exactly along the lines predicted by the DSP as proposed by Beck, Krasikova, et al. (2009). In the remainder of the paper, I turn to the question of how to best represent this variation in the grammar.

\section{Lexical variation?}

The investigation into the grammar of gradability in Washo has revealed cross-linguistic variation in the inventory of functional degree morphology, which is systematically absent in this language. I have proposed that this variation in the functional domain can easily be accounted for by invoking a parameter on variation in the lexicon, namely the DSP of Beck, Krasikova, et al. (2009). In other words, the presence or absence of degree morphology tracks a distinction in the lexical semantics of gradable predicates across languages.

There are precedents within the framework of truth-conditional semantics for positing parametric lexical variation to account for cross-linguistic variation in some domain of functional morphology. Notably, Chierchia (1998) proposes the Nominal Mapping Parameter on the denotations of bare nouns across languages. In essence, bare nouns may be predicative or argumental, where the former denote properties of individuals, while the latter denote kinds (Carlson 1977). Chierchia furthermore argues that a language's setting of this parameter has consequences for nominal morphosyntax. Languages where bare nouns are always of the argumental type (e.g., Mandarin Chinese) are those that lack a singular/plural distinction, and have a generalized classifier system. By contrast, languages where bare nouns are always of the predicative type (e.g., French) lack bare arguments, requiring nouns to always combine with a determiner to appear in argument position. Languages like English are of a mixed type, where a subset of bare nouns can appear as bare arguments (i.e., bare plurals and mass nouns). Thus, in Chierchia's system, cross-linguistic variation in the logical type of nouns (i.e., at the lexical level) corresponds to variation observed in the morphosyntax of nominal projections (plural formation, determiners, classifiers). ${ }^{21}$

At the same time, a parameter on the presence vs. absence of a particular sort of variable on the basis of the absence of a functional category may seem

21 See Chung (2000) and Wilhelm (2008) for critiques of the Nominal Mapping Parameter, based on data from Indonesian and Dëne Sųłiné, respectively. 
a bit extreme. For instance, no researchers investigating morphologically tenseless languages, to my knowledge, have proposed that such languages lack variables for times. Rather, variables for times in such languages just receive their values in ways different from English and other tensed languages, for example via aspectual morphemes, null tenses, or other temporal operators (see e.g., Bittner 2005 on Kalaallisut; Lin 2006 on Mandarin; Matthewson 2006 on St'át'imcets; Tonhauser 2011 on Paraguayan Guaraní). That is, in the domain of temporal semantics, a lack of morphological tense does not lead us to conclude that a language makes no reference to times as a semantic primitive. This therefore represents a case where a lack of a functional category does not correlate with a semantic parameter over the presence or absence of a basic type in the language, in contrast with the proposal put forth here regarding the status of degrees. ${ }^{22}$

Recall also Matthewson's (2001) assertion that parametric solutions to cross-linguistic variation weaken the strong universalist hypothesis. If a parametric solution is proposed, it must be made on the basis of "considerable empirical advantages" over a solution that maintains universality.

In view of this, one might wonder whether positing the DSP is the right way to go about accounting for the variation between English and Washo. I have already argued extensively in the previous section that gradable adjectives in Washo should not be analyzed as containing a degree variable, as is the standard view for English. But what if the standard view for English is not correct? Several authors have in fact pursued analyses treating gradable adjectives in English as vague degreeless predicates, just as I have proposed for Washo (Kamp 1975, Klein 1980, 1991, van Rooij 2011a,b, Burnett 2014). If these approaches are correct for English, then we cannot classify the variation between English and Washo as lexical - the source of variation must lie elsewhere.

In the following section I outline the degreeless analysis of degree constructions in English, largely drawing from the recent analysis of van Rooij (2011a,b). I identify those aspects of the analysis that would have to be amended to capture the patterns observed in Washo. On the one hand, the conclusion reached there echoes the one based on the DSP: the metalanguage that provides for an empirically adequate analysis of Washo must lack certain elements that are needed (or at least justified) for the characterization of

22 The comparison here with tense is not quite balanced, since languages lacking morphological tense nevertheless have temporal morphology such as aspect, temporal adverbs, etc., whereas I am arguing that Washo has absolutely no morphology that manipulates degrees in any way. 
Degree semantics and cross-linguistic variation

English, even though those elements are not stated in terms of degrees. On the other hand, the sorts of elements that are missing under this alternative do not form a unified class, suggesting that an analysis for variation in terms of the DSP is more parsimonious overall. I then end the section by briefly outlining an analysis for English offered by Wellwood (2014), which shares features of both the degree-based and vague predicate analyses. I argue that such an analysis does not make the right predictions for the cross-linguistic facts discussed in this paper.

\section{A degree-free alternative}

There are two major motivations for preferring a vague predicate analysis for scalar predicates over a degree-based analysis, even for English. For starters, Klein (1980) argues that implicating degrees introduces "unjustified complexity" (p. 4) into the model. Indeed, an analysis that gets all the facts right without positing extra theoretical machinery would be more parsimonious than one that requires innovating an extra logical type, assuming equal empirical coverage. Perhaps a more serious objection to the degree analysis of gradable predicates has to do with the way in which the positive (unmarked) form is interpreted. Under the degree analysis, a gradable predicate cannot be directly applied to an individual, since it is not the right semantic type. The degree analysis provides a fix for this by positing a null morpheme pos (see (3) in Section 1). Much typological work has observed that across languages, the comparative form tends to be more marked than the positive form (Ultan 1972, Stassen 1985, Bobaljik 2012), whereas under the degree analysis both the positive form and the comparative form are marked by degree morphology. Worse, there seem to be no languages at all that overtly lexicalize pos.

However, despite these objections, certain authors have argued that a degree analysis should be maintained for English. First, as argued by von Stechow (1984), the vague predicate analysis has difficulty with differential measure phrases in comparatives, such as (55). 
(55) Amy is six inches taller than Betty.

He proposes to treat differential measure phrases as denoting degrees, and furthermore argues that since degrees need to be used in cases like (55), they should be generalized to the whole grammar of gradability.

A second objection against the empirical adequacy of the degree-free analysis for English is raised by Kennedy (2011). Kennedy argues that the vague predicate analysis has difficulty with distinguishing explicit and implicit comparisons, in particular in crisp judgment contexts (as in (56)).

(56) Context: Amy is 5 feet 2 inches tall and Betty is 5 feet 1 inch tall.

a. Amy is taller than Betty.

b.\#Compared to Betty, Amy is tall.

Under a degree-based account, both the comparative form and the positive form are derived by adding degree morphology to an underlying element that contains a degree variable. In the case of (56a), this underlying form combines with the comparative morpheme, resulting in a predicate that is true if Amy's height exceeds Betty's by any non-zero degree. By contrast, in the case of (56b), this underlying form combines with pos to yield a vague predicate, which is then subject to the Similarity Constraint (recall (20)). Like von Stechow, Kennedy concludes that the degree analysis for English is in a better position to handle the empirical differences between the positive and comparative forms of adjectives on the one hand and the comparisons in (56a) and (56b) on the other hand with respect to vagueness and crisp judgments.

Although the degree analysis has become standard, some authors have developed more sophisticated tools to circumvent these objections while still maintaining a degree-free analysis for English. I outline these immediately below.

\subsection{Simulating degree effects without degrees}

Recently, van Rooij (2011a,b) has provided a vague predicate analysis of degree constructions in the spirit of Klein $(1980,1991)$ using tools from measurement theory (Krantz et al. 1971). Crucial to the account is a fourway classification of scales, based on their complexity. ${ }^{23}$ The first type is

23 Also see Sassoon $(2010,2013)$ for an introduction and discussion of the different scale types used in measurement theory. 
Degree semantics and cross-linguistic variation

called a nominal scale, which is essentially used for classification and for which there are no greater than or less than relations defined for the values of nominal scales. The second type is an ordinal scale, where objects are assigned values on a scale based on rank order. Greater than and less than relations are defined for ordinal scales, but not operations such as addition or subtraction. The third type is called an interval scale, which can represent differences between values, but not ratios or addition of scalar values. Realworld examples of interval scales are the Celsius and Fahrenheit scales for temperature (Sassoon 2010). The fourth and most complex type are ratio scales, which have all the features of interval scales, plus the operations of addition and multiplication of values. As shown by van Rooij, the properties of degree scales on the standard degree analysis correspond to those of interval and ratio scales. That is, the relevant properties of degrees that make them indispensable according to the standard degree analysis (and in particular for von Stechow and Kennedy's arguments) can be simulated by making reference to interval and/or ratio scales.

With respect to von Stechow's challenge, differential measure phrases can be captured in this system in the following way. Let $\langle X, R, \circ\rangle$, be a ratio ordering scale, where $X$ is a non-empty set of individuals, $R$ a binary relation on $X$ and $\circ$ a concatenation operation such that for a mapping $f$ of individuals to real numbers, $f(x \circ y)=f(x)+f(y)$. The truth conditions of (55) can now be stated along the lines of (57), where $f$ is a mapping from individuals to heights.

(57) $\exists f[f(a)=f(b \circ 6$ in $)]$

As for the interpretation of unit names like inch here, we can follow a Kleinstyle analysis whereby they name the equivalence class of objects measuring exactly one inch. These degree-like objects can then be multiplied by scalars, and concatenated with other like objects, given that these operations are defined for ratio scales. ${ }^{24}$

As for Kennedy's challenge, van Rooij (2011a) argues that the distinction between implicit and explicit comparison boils down to a distinction between two types of orderings: a SEMI-ORDER provides the basis for interpreting an implicit comparison, while a (STRICT) WEAK ORDER is required for explicit comparison. These orderings are defined as in (58)-(59).

24 See Sassoon (2010) for a more detailed treatment of measure phrases within measurement theory. 
(58) A SEMI-ORDER is a structure $\langle X, R\rangle$, with $R$ a binary relation on $X$, a non-empty set of individuals, that satisfies the following conditions:

a. Irreflexivity: $\forall x: \neg R(x, x)$

b. Interval-Order: $\forall x, y, v, w:(R(x, y) \wedge R(v, w)) \rightarrow$

$$
(R(x, w) \vee R(v, y))
$$

c. Semi-Transitivity: $\forall x, y, z, v:(R(x, y) \wedge R(y, z)) \rightarrow$

$$
(R(x, v) \vee R(v, z))
$$

(van Rooij 2011a, p. 78)

(59) A (STRICT) WEAK ORDER is a structure $\langle X, R\rangle$, with $R$ a binary relation on $X$, a non-empty set of individuals, that satisfies the following conditions:
a. Irreflexivity: $\forall x: \neg R(x, x)$
b. Transitivity: $\forall x, y, z:(R(x, y) \wedge R(y, z)) \rightarrow R(x, z)$
c. Almost Connectedness: $\forall x, y, z: R(x, y) \rightarrow(R(x, z) \vee R(z, y))$

(van Rooij 2011a, p. 75)

In measurement theory terms, if $f(x)$ is a measure of $x$ on some dimension, a semi-order $\succ_{P}$ can be defined as follows, where $\epsilon$ is some fixed value (a “margin of error” in van Rooij's terms):

$$
x \succ_{P} y \text { iff } f(x)>f(y)+\epsilon
$$

The presence of a margin of error $\epsilon$ corresponds to the intuition that implicit comparisons require the objects being compared to differ significantly along the compared dimension (i.e., Kennedy's crisp judgment test). When $\epsilon=0$, (6o) is a weak order. The presence of $\epsilon$ captures the vagueness associated with implicit comparisons. It is not merely enough for one individual's measure on the scale to be ordered above the other's; there must be a significant difference between their respective measures.

Additionally, the two types of comparisons impose different constraints on the models relative to which they are interpreted. For implicit comparisons like in (56b), the vague predicate tall is evaluated with respect to a context that includes only Amy and Betty. The crisp judgment effect arises due to the Similarity Constraint: Amy and Betty differ only slightly with respect to height, so we are unwilling to judge the proposition that Amy is tall true and the proposition that Betty is tall false. For explicit comparisons like (56a), van Rooij proposes a constraint on models that requires the existence 
Degree semantics and cross-linguistic variation

of "witnesses" to the compared objects that can be used to construct a comparison class that obviates the Similarity Constraint. That is, there must exist in the model enough other individuals to compare Amy and Betty to, in order to ensure that Amy stands out relative to Betty. This could be either an individual who is like Betty but significantly shorter than Amy, or one who is like Amy but significantly taller than Betty. The extra individuals in the model ensure that the small difference in height between Amy and Betty becomes significant enough to place Amy under the positive extension of tall and Betty under the negative extension, allowing the comparative to go through. Thus, degree-like effects can be derived under this system to take care of the distinction between explicit and implicit comparisons. ${ }^{25}$

In sum, the degree-free analysis developed by van Rooij is able to precisely simulate degree effects without actually adding degrees as a basic type in the semantic ontology. Thus, von Stechow and Kennedy's objections to the vague predicate analysis for English are neutralized, as the resulting system can handle even the difficult cases where degrees were argued to be necessary. Under this analysis then, the DSP cannot be invoked to account for the variation between English and Washo, since gradable predicates in both languages are simply vague $\langle e, t\rangle$ predicates. Cross-linguistic variation under this system must therefore be handled in a different way.

\subsection{Accounting for variation}

The van Rooij-style analysis outlined above invoked special machinery to account for differential measure phrases and to capture the explicit/implicit comparison distinction. Since Washo has neither of these features, it follows then that Washo should lack these very mechanisms.

First, recall that measure phrases, differential or otherwise, are absent in Washo. Under this analysis, Washo therefore would lack (a) the ability to construct unit-length equivalence classes which are lexicalized by unit names like inch, and (b) ratio scales where the operations of concatenation and multiplication are defined. Second, to account for the distinction between explicit and implicit comparison, two more assumptions that were necessary for English must be absent in Washo. Namely, Washo would lack the ability

25 As Kennedy (2011) points out, such a move introduces abstract entities to the model that need not exist in the domains of gradable predicates. That is, in order to explain the crisp judgment facts, the vague predicate analysis must introduce abstract ontological objects after all, essentially re-inventing degrees under a different guise. 
to set the "margin of error" value $\epsilon$ in (6o) to o, and also lack the ability to construct comparison classes containing abstract "witness" individuals to obviate the Similarity Constraint.

Thus, under the vague predicate analysis, the conclusion reached about how to handle Washo is similar in spirit to that of the degree analysis in terms of the DSP. Simply put, the formal tools and abstract objects in the metalanguage ontology and operations over them are not necessary for the analysis of Washo. The analyses simply differ in what sorts of objects those are. A degree-free analysis is therefore also able to capture the variation between English and Washo, so long as we grant that certain features of the analysis for English can be unavailable for other languages. In fact, Sassoon (2013) suggests that languages may very well vary in terms of what sorts of scales they make use of. For instance, Washo would lack interval and ratio scales, since these are the ones where more complex operations are defined that can simulate degree effects. ${ }^{26}$

Although a vague predicate analysis can indeed find ways to account for the variation between English and Washo, I would like to point out one way in which it is a somewhat less satisfactory account, compared to the standard degree analysis. Under van Rooij's account, the relevant phenomena require different pieces of machinery to get all the facts right for English. Correspondingly, the sorts of operations that must be absent from Washo on this account do not form a unified class. There is no explanation for why Washo should lack exactly the special mechanisms that van Rooij appeals to for his account of differential measure phrases and explicit comparison (e.g., the construction of certain types of comparison and equivalence classes). The degree analysis, meanwhile, can easily explain the Washo facts, namely by appealing to the DSP. Under this view, all degree constructions are analyzed in terms of operations over degrees, so it follows that a language without degrees should lack all the corresponding operations, which is exactly what we find with Washo.

While van Rooij has shown that the range of English data can indeed be accounted for without degrees, the cross-linguistic facts here can be taken as an indirect argument in favor of the degree analysis for English, since it is

26 Sassoon further suggests that Beck, Krasikova, et al.'s other parameters may also be reduced to the differences between scale types in measurement theory. However, it is not obvious how this idea could account for all of Beck, Krasikova, et al.'s parameters, one of which is a syntactic parameter that determines whether the specifier of DegP may be overtly filled. This is a question that must be left for future work. 
Degree semantics and cross-linguistic variation

quite simple to state the difference between English and Washo in terms of a general parameter on the presence/absence of degree variables in gradable predicates.

\subsection{Introducing degrees another way}

In this subsection, I briefly outline a recent analysis of degree constructions by Wellwood (2014) that in some sense represents a middle ground between the vague predicate analysis and the degree analysis for English. Under Wellwood's analysis, gradable predicates do not contain a degree variable, but may acquire one in order to participate in degree constructions. Like the more traditional vague predicate analysis, Wellwood's analysis would therefore not locate the difference between English and Washo in the lexical semantics of gradable predicates, but rather in whether or not gradable predicates in a language have the ability to acquire a degree variable from somewhere else.

Under Wellwood's analysis, degrees are introduced by much, which combines with a degreeless predicate and returns a degree relation. Simplifying somewhat, this operation can be modeled as in (61) below, where $\mathbf{m}$ tracks the dimension associated with a predicate $P$. The application of $\mathbf{m}$ to $P$ and an individual returns the degree to which that individual holds $P .{ }^{27}$

$$
\llbracket m u c h \rrbracket=\lambda P_{\langle e, t\rangle} \lambda d \lambda x \cdot \mathbf{m}(P)(x) \succeq d
$$

For most gradable adjectives in English, much is silent (see Bresnan 1973). However, Wellwood observes that much is obligatory when verbs and nouns enter into degree constructions, as shown in (62)-(63). ${ }^{28}$ Given that verbs and nouns are standardly assumed not to contain degree variables themselves, it stands to reason that much has the job of introducing degrees and licensing degree constructions in these cases. Wellwood's innovation is thus to generalize this view to gradable adjectives as well, and claim that they do not themselves contain a degree variable either.

27 Wellwood's formal implementation is quite different, since she makes different assumptions about the underlying semantics of the degree-free predicate $P$ and the mode of composition between $P$ and much. I direct interested readers to her dissertation for the details, including a formulation of the restrictions on the value of $\mathbf{m}$.

28 Wellwood assumes, following Bresnan (1973) and Hackl (2001), that more is underlyingly much+-er. Note that versions of (63b) and (63c) (Al ran as Bill did; How did Al run?) are acceptable under a manner interpretation; see Rett (2013) for discussion. 
(62) a. Al ate more soup than Bill did.

b. Al ate as *(much) soup as Bill did.

c. How *(much) soup did $\mathrm{Al}$ eat?

(63) a. Al ran more than Bill did.

b. Al ran as *(much) as Bill did.

c. How *(much) did $\mathrm{Al}$ run?

Under this style of analysis, the locus of variation between English and Washo would be in the availability of much in (61). This analysis makes predictions parallel to those of the DSP: it predicts the complete absence of degree constructions in Washo, since this is entailed by the absence of much.

However, there is evidence from Washo that casts doubt on Wellwood's proposal for much being uniformly the source of degree variables. It involves the distribution of the Washo word t'e:k'e?, which is often translated as 'much' or 'many',29 and which combines with both nouns and verbs to yield an interpretation of "large quantity", as shown in (64)-(65).

(64) mé:hu t’á:gim t’é:k'e? PíPwi

merhu t'argim t'erk'e? P-i?iw-i

boy pine nuts many 3-eat-IPFV

'The boy ate lots of pine nuts.'

(65) dihámu?áyawi t'é:k'e? lé?wigi Lé?i

di-hamu-Payaw-i t'erk'e? le-i?iw-i-gi L-e?-i

1-feel-good-IPFV much 1-eat-IPFV-SUBJ.REL 1-COP-IPFV

'When I am happy, I eat a lot.'

Just like English much, Washo t'e:k'e? is used for nominal and verbal comparisons, but does not appear in comparisons based on gradable predicates. The example in (16), repeated here as (66), shows that t'e:k'e? is used to make amount comparatives, while (67) shows t'e:k'e? being used with a verbal comparison. Without t'e:k'e?, these sentences aren't interpreted as comparisons.

29 In Washo, t'e:k'e? does not track a mass/count distinction along the lines of English much/many. I gloss it as 'much' or 'many' as appropriate for the English translations. 
Degree semantics and cross-linguistic variation

(66) Beverly t'é:k'e? t’á:gim ?ípwi demuc'úc'uya t'é:k'eya

Beverly t'e:k'e? t'a:gim ?-îiw-i de-muc'uc'u-ya t'e:k'e?-ya

Beverly many pine nuts 3-eat-IPFV NMLZ-sweet-NC many-NC

Pi?wé:sa?

P-iPiw-ers-a?

3-eat-NEG-AOR

'Beverly ate more pine nuts than berries.'

(Literally: 'Beverly ate many pine nuts, she didn't eat many berries.')

(67) mé:hu t'é:k'e? MúPuši šáwlamhu t'é:k'eya

me:hu t'exk'e? Mu-i?iš-i šawlamhu t'erk'e?-na

boy much run-forward-IPFV girl much-NC

MúPušé:saš

Mu-i?išs-ers-a?-š

run-forward-NEG-AOR-SR

'The boy ran more than the girl.'

(Literally: 'The boy ran a lot, the girl didn't run a lot.')

Comparisons made using t'e:k'e? show the same semantic behavior as other conjoined comparisons. In particular, they also give rise to norm-related interpretations, as shown in (68).

(68) Context: Comparing a man who is 85 years old, and woman who is 75 years old (i.e., both are old).

$$
\begin{array}{lll}
\text { \#t'érliwhu t'érk'e? dewgálisi? } & \text { k'éPi } & \text { daPmó?mo? } \\
\text { t'erliwhu t'erk'e? de-w-galis-i? } & \text { k'-e?-i } & \text { daPmo?mo? } \\
\text { man } & \text { many NMLZ-STATIC-winter-ATTR } & \text { 3-COP-IPFV woman } \\
\text { t'é:k'eya dewgálisi? } & \text { k'áPaš } & \\
\text { t'erk'e?-ya de-w-galis-i? } & \text { k'-e?-a?-š } & \\
\text { many-NC NMLZ-STATIC-winter-ATTR } & \text { 3-COP-AOR-SR }
\end{array}
$$

Intended: 'The man is older than the woman.'

(Literally: 'The man is many years, the woman is not many years.')

What this data shows is that t'e:k'e? in Washo has a similar distribution to much in English, occurring with nominal and verbal comparisons, but absent in comparisons based on gradable predicates. But on Wellwood's account, the fact that much does not appear on the surface in degree constructions with gradable adjectives is simply a morphological accident. The fact that the 
exact same morphological pattern surfaces in Washo as well, a language that displays very different properties from English with respect to comparison and degree constructions, suggests there is a generalization being missed.

\section{Conclusion}

Recall that Matthewson (2001) and von Fintel \& Matthewson (2008) advocate a methodology for cross-linguistic research in semantics whereby the starting point is a null hypothesis of no variation, followed by rigorous testing in particular languages. After such rigorous testing of the grammar of gradability in Washo, I have shown that this language lacks the category of degree morphemes that bind a degree variable in gradable predicates. In particular, this language lacks comparative, superlative, and equative morphemes, measure phrases, and degree adverbs. I proposed to account for these facts in terms of variation in the lexicalization of gradable predicates across languages, specifically in whether they introduce degrees or not. The Washo data thus confirm a similar conclusion that was reached by Beck, Krasikova, et al. (2009) for Motu, who were the first to propose the Degree Semantics Parameter in (7). Since the DSP was posited only on the basis of a medium-depth study of Motu, the detailed study of Washo presented here confirms the existence of languages of this type. Although a theory of cross-linguistic variation may be couched within alternative analyses of gradability, the analysis in terms of the DSP provides a straightforward explanation for the differences between English-like and Washo-like languages, and elegantly accounts for the fact that Washo lacks the entire paradigm of degree constructions. My comparison between the DSP account and its alternatives points to avenues for further exploring the differences in the empirical predictions made by these analytical options, which may be relevant for future cross-linguistic research.

I conclude by reflecting on some of the consequences of the analysis proposed here. First, under my analysis, there are languages that simply lack a basic semantic type, namely degrees. This raises the question of why degrees should be subject to this kind of cross-linguistic variation. It is much less obvious that other logical types should be missing from a language (e.g., individuals, events, worlds), or what a language would look like if such a gap were to exist. I speculate that this point can be linked to the idea that degrees are not in fact basic on a par with other simple types. For instance, Cresswell (1976) derives degrees from equivalence classes of individuals, and more 
Degree semantics and cross-linguistic variation

recently Anderson \& Morzycki (To appear) treat degrees as being derived from state kinds. And of course, deriving degree-like effects indirectly is at the heart of the analyses by Klein and van Rooij. This view of degrees might be able to give us a handle on why a parameter like the DSP might exist in the first place: if degrees don't come "for free" as basic elements in the model, then languages differ on whether they choose to derive them.

Second, given that I have followed Beck, Krasikova, et al. (2009) in stating variation in terms of a parameter, this raises the question of what exactly it means for there to be a semantic parameter, and how far-reaching its consequences are. In my view, the DSP is a way of simply stating the difference between English and Washo with respect to the analysis of gradable predicates and related degree constructions (or lack thereof). It is a question for future research whether degrees are completely absent in Washo, or whether there may be other corners of grammar that nevertheless implicate degrees. For instance, Kennedy (2013) analyzes numerals as denoting higher-order predicates of degrees. Washo does have a fully fledged numeral system (see examples (42), (54) and Jacobsen 1996), and so if a degree-based analysis of numerals is correct, then it may just be that the lack of degrees in this language is restricted to the grammar of gradable predicates, with degrees being available elsewhere in the language. ${ }^{30}$

Finally, this study highlights a question that arises in the context of crosslinguistic research where a language is claimed to lack some category: just how much can a language do without? This question is also posed by Deal (2011) in the context of her analysis of the non-epistemic modal -o'qa in Nez Perce as a possibility modal which lacks a necessity counterpart. As Deal puts it: "the option of doing without certain expressions ... tells us something about how precise a language must be to facilitate efficient communication" (p. 583). Evidently, a language can make do without degrees for expressing comparison, which in fact should be unsurprising given the general features of vagueness and scalarity that support making comparisons in both English and Washo. Future research on other areas of grammar in understudied

30 Relatedly, there is the question of how a child comes to learn that s/he is speaking a +/-DSP language. See Hohaus, Tiemann \& Beck (2014) who provide acquisition data from English and German children that support the view that children start off with a -DSP language, only later acquiring the positive parameter setting. That is, a -DSP language is available to any language learner, but Washo learners never make the step to a +DSP language during acquisition. 
languages will undoubtedly continue to inform us on the range and limits of this type of variation in the semantic component of natural language.

\section{References}

Anderson, Curt \& Marcin Morzycki. To appear. Degrees as kinds. To appear in Natural Language and Linguistic Theory.

Barker, Chris. 2002. The dynamics of vagueness. Linguistics and Philosophy 25. 1-36. http://dx.doi.org/10.1023/A:1014346114955.

Bartsch, Renate \& Theo Vennemann. 1972. The grammar of relative adjectives and comparison. Linguistische Berichte 20. 19-32.

Beck, Sigrid, Sveta Krasikova, Daniel Fleischer, Remus Gergel, Stefan Hofstetter, Christiane Savelsberg, John Vanderelst \& Elisabeth Villalta. 2009. Crosslinguistic variation in comparative constructions. In Jeroen van Craenenbroeck \& Johan Rooryck (eds.), Linguistic Variation Yearbook, vol. 9, 1-66. Philadelphia, PA: John Benjamins. http://dx.doi.org/10.1075/livy.9. olbec.

Beck, Sigrid, Toshiko Oda \& Koji Sugisaki. 2004. Parametric variation in the semantics of comparison: Japanese vs. English. Journal of East Asian Linguistics 13(4). 289-344. http://dx.doi.org/10.1007/s10831-004-1289-o.

Beltrama, Andrea \& M. Ryan Bochnak. To appear. Intensification without degrees crosslinguistically. To appear in Natural Language and Linguistic Theory.

Bierwisch, Manfred. 1989. The semantics of gradation. In Manfred Bierwisch \& Ewald Lang (eds.), Dimensional Adjectives: Grammatical Structure and Conceptual Interpretation, 71-261. Berlin: Springer-Verlag.

Bittner, Maria. 2005. Future discourse in a tenseless language. Journal of Semantics 22. 339-387. http://dx.doi.org/10.1093/jos/ffho29.

Bobaljik, Jonathan David. 2012. Universals in comparative morphology. Cambridge, MA: MIT Press.

Bochnak, M. Ryan. 2012. Managing vagueness, imprecision and loose talk in Washo: The case of šemu. Semantics of Underrepresented Languages of the Americas (SULA) 6. 1-14.

Bochnak, M. Ryan. 2013. Cross-linguistic variation in the semantics of comparatives. Chicago: University of Chicago $\mathrm{PhD}$ thesis.

Bochnak, M. Ryan \& Elizabeth Bogal-Allbritten. 2015. Investigating gradable predicates, comparison, and degree constructions in underrepresented 
Degree semantics and cross-linguistic variation

languages. In M. Ryan Bochnak \& Lisa Matthewson (eds.), Methodologies in semantic fieldwork, 110-134. Oxford University Press.

Bochnak, M. Ryan, Timothy Grinsell \& Alan C L Yu. 2011. Copula agreement and the stage-level/individual-level distinction in Washo. Workshop on Structure and Constituency in Languages of the Americas (WSCLA) 16. $1-10$.

Bochnak, M. Ryan \& Alice Rhomieux. 2013. Limited noun incorporation in Washo. International Journal of American Linguistics 79(2). 253-281. http: //dx.doi.org/10.1086/669630.

Bresnan, Joan. 1973. Syntax of the comparative clause construction in English. Linguistic Inquiry 4(3). 275-343.

Burnett, Heather. 2014. A delineation solution to the puzzles of absolute adjectives. Linguistics and Philosophy 37(1). 1-39. http://dx.doi.org/10. 1007/s10988-014-9145-9.

Carlson, Gregory. 1977. Reference to kinds in English. Amherst, MA: University of Massachusetts PhD thesis.

Chierchia, Gennaro. 1998. Reference to kinds across languages. Natural Language Semantics 6. 339-405. http://dx.doi.org/10.1023/A:1008324218506. Chung, Sandra. 2000. On reference to kinds in Indonesian. Natural Language Semantics 8. 157-171. http://dx.doi.org/10.1023/A:1026527925514.

Cresswell, Max J. 1976. The semantics of degree. In Barbara Partee (ed.), Montague Grammar, 261-292. New York, NY: Academic Press.

Deal, Amy Rose. 2011. Modals without scales. Language 87(3). 559-585. http: //dx.doi.org/10.1353/lan.2011.0060.

Fara, Delia Graff. 200o. Shifting sands: An interest-relative theory of vagueness. Philosophical Topics 28. Originally published under the name "Delia Graff", 45-81. http://dx.doi.org/10.5840/philtopics20002816.

von Fintel, Kai \& Lisa Matthewson. 2008. Universals in semantics. The Linguistic Review 25. 139-201. http://dx.doi.org/10.1515/TLIR.2008.004.

Grano, Thomas. 2012. Mandarin hen and Universal Markedness in gradable adjectives. Natural Language and Linguistic Theory 30. 513-565. http: //dx.doi.org/10.1007/s11049-011-9161-1.

Grano, Thomas \& Christopher Kennedy. 2012. Mandarin transitive comparatives and the grammar of measurement. Journal of East Asian Linguistics 21. 219-266. http://dx.doi.org/10.1007/s10831-012-909o-Y.

Gumiel-Molina, Silvia, Norberto Moreno-Quibén \& Isabel Pérez-Jiménez. To appear. A syntactic approach to the relative/absolute distinction: The 
case of adjectives in copular sentences in Spanish. To appear in Natural Language and Linguistic Theory.

Hackl, Martin. 2001. Comparative quantifiers. Cambridge, MA: Massachusetts Institute of Technology $\mathrm{PhD}$ thesis.

Haspelmath, Martin \& Oda Buchholz. 1998. Equative and similative constructions in the languages of Europe. In Johan van der Auwera \& Dónall Ó Baoill (eds.), Adverbial constructions in the languages of Europe, 277-334. Berlin: Mouton de Gruyter.

Hayashishita, J.-R. 2009. Yori-comparatives: A reply to Beck et al. (2004). Journal of East Asian Linguistics 18. 65-100. http://dx.doi.org/10.1007/ s10831-009-9040-5.

Heim, Irene. 1985. Notes on comparatives and related matters. Ms. University of Texas at Austin.

Heim, Irene. 2001. Degree operators and scope. In Caroline Féry \& Wolfgang Sternefeld (eds.), Audiatur vox sapientiae, 214-239. Berlin: AkademieVerlag.

Hohaus, Vera. 2012. Directed motion as comparison: Evidence from Samoan. Semantics of Underrepresented Languages Outside of the Americas (SULAbar) 1. 335-348.

Hohaus, Vera, Sonja Tiemann \& Sigrid Beck. 2014. Acquisition of comparative constructions. Language Acquisition 21. 215-249. http://dx.doi.org/10. 1080/10489223.2014.892914.

Jacobsen, William H. 1964. A grammar of the Washo language. University of California, Berkeley PhD thesis.

Jacobsen, William H. 1980. Washo bibartite verb stems. In Kathryn Klar, Margaret Langdon \& Shirley Silver (eds.), American Indian and Indo-European studies: papers in honor of Madison S. Beeler, 85-99. Berlin: Mouton.

Jacobsen, William H. 1996. Beginning Washo. Carson City, NV: Nevada State Museum.

Kamp, Hans. 1975. Two theories of adjectives. In Edward Keenan (ed.), Formal semantics of natural language, 123-155. Cambridge: Cambridge University Press.

Kennedy, Christopher. 1997. Projecting the adjective: the syntax and semantics of gradability and comparison. University of California, Santa Cruz $\mathrm{PhD}$ thesis.

Kennedy, Christopher. 2007a. Modes of comparison. Chicago Linguistic Society (CLS) 43. 141-165. 
Degree semantics and cross-linguistic variation

Kennedy, Christopher. 2007b. Vagueness and grammar: The semantics of relative and absolute gradable adjectives. Linguistics and Philosophy 30(1). 1-45. http://dx.doi.org/10.1007/s10988-0o6-90o8-o.

Kennedy, Christopher. 2011. Vagueness and comparison. In Paul Egré \& Nathan Klinedinst (eds.), Vagueness and Language Use, 73-97. New York, NY: Palgrave MacMillan.

Kennedy, Christopher. 2013. A scalar semantics for scalar readings of number words. In Ivano Caponigro \& Carlo Cecchetto (eds.), From grammar to meaning: The spontaneous logicality of language, 172-200. New York, NY: Cambridge University Press.

Kennedy, Christopher \& Louise McNally. 2005. Scale structure, degree modification and the semantics of gradable predicates. Language 81(2). 345-381. http://dx.doi.org/10.1353/lan.2005.0071.

Klein, Ewan. 1980. A semantics for positive and comparative adjectives. Linguistics and Philosophy 4(1). 1-46. http://dx.doi.org/10.1007/BFo0351812.

Klein, Ewan. 1991. Comparatives. In Arnim von Stechow \& Dieter Wunderlich (eds.), Semantik: Ein internationales Handbuch der zeitgenössischen Forschung, 673-691. Berlin: Walter de Gruyter.

Krantz, David, R. Duncan Luce, Patrick Suppes \& Amos Tversky. 1971. Foundations of measurement: Additive and polynomial representations. San Diego, CA \& London: Academic Press.

Lassiter, Daniel. 2011. Vagueness as probabilistic linguistic knowledge. In Rick Nouwen, Robert van Rooij, Uli Sauerland \& Hans-Christian Schmidt (eds.), Vagueness in communication, 197-215. Dordrecht: Springer.

Lin, Jo-wang. 2006. Time in a language without tense: The case of Chinese. Journal of Semantics 23. 1-53. http://dx.doi.org/10.1093/jos/ffho33.

Marsack, C. C. 1975. Samoan. 4th edition. Norwich: The English Universities Press.

Matthewson, Lisa. 2001. Quantification and the nature of crosslinguistic variation. Natural Language Semantics 9. 145-189. http://dx.doi.org/10. 1023/A:1012492911285.

Matthewson, Lisa. 2004. On the methodology of semantic fieldwork. International Journal of American Linguistics 70(4). 369-415. http://dx.doi.org/ $10.1086 / 429207$.

Matthewson, Lisa. 2006. Temporal semantics in a superficially tenseless language. Linguistics and Philosophy 29. 673-713. http://dx.doi.org/10. 1007/s10988-006-9010-6. 
McNabb, Yaron. 2012a. Cross-categorial modification of properties in Hebrew and English. Semantics and Linguistic Theory (SALT) 22. 365-382.

McNabb, Yaron. 2012b. The syntax and semantics of degree modification. Chicago, IL: University of Chicago PhD thesis.

McNally, Louise. 2011. The relative role of property type and scale structure in explaining the behavior of gradable adjectives. In Rick Nouwen, Robert van Rooij, Uli Sauerland \& Hans-Christian Schmitz (eds.), Vagueness in communication, 151-168. Dordrecht: Springer.

Rett, Jessica. 2007. Antonymy and evaluativity. Semantics and Linguistic Theory (SALT) 17. 210-227.

Rett, Jessica. 2013. Similatives and the argument structure of verbs. Natural Language and Linguistic Theory 31(4). 1101-1137. http://dx.doi.org/10. 1007/s11049-013-9201-0.

van Rooij, Robert. 2011a. Implicit versus explicit comparatives. In Paul Egré \& Nathan Klinedinst (eds.), Vagueness and language use, 51-72. New York, NY: Palgrave MacMillan.

van Rooij, Robert. 2011b. Measurement and interadjective comparisons. Journal of Semantics 28(3). 335-358. http://dx.doi.org/10.1093/jos/ffqo18.

Rotstein, Carmen \& Yoad Winter. 2004. Total adjectives vs. partial adjectives: Scale structure and higher-order modifiers. Natural Language Semantics 12(3). 259-288. http://dx.doi.org/10.1023/B:NALS.ooooo34517.56898.9a.

Sapir, Edward. 1944. Grading, a study in semantics. Philosophy of Science 11(2). 93-116.

Sassoon, Galit Weidman. 2010. Measurement theory in linguistics. Synthese 174(1). 151-180. http://dx.doi.org/10.1007/s11229-009-9687-5.

Sassoon, Galit Weidman. 2013. Vagueness, gradability, and typicality: The interpretation of adjectives and nouns. Boston, MA: Brill.

Sawada, Osamu. 2009. Pragmatic aspects of implicit comparison: An economybased approach. Journal of Pragmatics 41(6). 1079-1103. http://dx.doi. org/10.1016/j.pragma.2008.12.004.

Schwarzschild, Roger. 2002. The grammar of measurement. In Brendan Jackson (ed.), Proceedings of Semantics and Linguistic Theory (SALT) XII. CLC Publications.

Schwarzschild, Roger. 2005. Measure phrases as modifiers of adjectives. Recherches Linguistiques de Vincennes 34. 207-228. http://rlv.revues.org/ 1401. 
Degree semantics and cross-linguistic variation

Shimoyama, Junko. 2012. Reassessing crosslinguistic variation in clausal comparatives. Natural Language Semantics 20(1). 83-113. http://dx.doi. org/10.1007/s11050-011-9076-8.

Stassen, Leon. 1985. Comparison and Universal Grammar. Oxford: Basil Blackwell.

von Stechow, Arnim. 1984. Comparing semantic theories of comparison. Journal of Semantics 3. 1-77. http://dx.doi.org/10.1093/jos/3.1-2.1.

Sudo, Yasutada. 2014. Hidden nominal structures in Japanese clausal comparatives. To appear in Journal of East Asian Linguistics.

Svenonius, Peter \& Christopher Kennedy. 2006. Northern Norwegian degree questions and the syntax of measurement. In Mara Frascarelli (ed.), Phases of Interpretation, 133-161. The Hague: Mouton de Gruyter.

Syrett, Kristen. 2007. Learning about the structure of scales: Adverbial modification and the acquisition of the semantics of gradable adjectives. Evanston, IL: Northwestern University PhD thesis.

Toledo, Assaf \& Galit Weidman Sassoon. 2011. Absolute vs. relative adjectives - Variance within vs. between individuals. Semantics and Linguistic Theory (SALT) 21. 135-154.

Tonhauser, Judith. 2011. Temporal reference in Paraguayan Guaraní, a tenseless language. Linguistics and Philosophy 34(3). 257-303. http://dx.doi. org/10.1007/s10988-011-9097-2.

Ultan, Russell. 1972. Some features of basic comparative constructions. In Working papers on language universals, 117-162. Stanford, CA: Language Universals Project, Committee on Linguistics.

Wellwood, Alexis. 2014. Measuring predicates. College Park, MD: University of Maryland $\mathrm{PhD}$ thesis.

Wilhelm, Andrea. 2008. Bare nouns and number in Dëne Sưłiné. Natural Language Semantics 16. 39-68. http://dx.doi.org/10.1007/s11050-0079024-9.

Williamson, Timothy. 1999. On the structure of higher-order vagueness. Mind 108(429). 127-143. http://dx.doi.org/10.1093/mind/108.429.127.

Zwarts, Joost. 1997. Vectors as relative positions: A compositional semantics of modified PPs. Journal of Semantics 14. 57-86. http://dx.doi.org/10. 1093/jos/14.1.57.

Zwarts, Joost \& Yoad Winter. 200o. Vector space semantics: A model-theoretic analysis of locative prepositions. Journal of Logic, Language, and Information 9. 169-211. http://dx.doi.org/10.1023/A:1008384416604. 
M. Ryan Bochnak

M. Ryan Bochnak

Department of Linguistics

1203 Dwinelle Hall

University of California, Berkeley

Berkeley, CA 94720-2650 USA

bochnak@berkeley.edu 